Submitted to International Journal of Fatigue in revised form, October 2007

\title{
Analysis of Surface Crack Growth under Rolling Contact Fatigue
}

\author{
D. Canadinc ${ }^{* \dagger}$, H. Sehitoglu, and K. Verzal \\ University of Illinois at Urbana-Champaign, Department of Mechanical Science and Engineering \\ 1206 W. Green St.Urbana, IL 61801, USA, Phone: +1 217 333-4112, Fax: + 1217 244-6534
}

Keywords: Surface crack; rolling contact; fatigue; crack tip opening; crack tip sliding; crack growth rate.

\begin{abstract}
Understanding the fatigue crack growth phenomenon in railheads requires a study of driving forces such as the crack tip opening and sliding displacements, under repeated rolling contact. Finite element simulations, allowing elastic-plastic deformation, and mixed-mode crack growth laws were utilized to demonstrate that the fatigue crack growth rates display a minimum after a finite amount of crack advance. These results have implications in designing strategies for optimum grinding or wear rates to limit fatigue crack growth, and thereby prolong rail life. During the simulations, the crack was allowed to advance, permitting residual deformations and stresses to be retained from cycle to cycle. The opening and closure of crack surfaces, under forward and reverse slip and stick conditions were monitored. Normal pressures of $1500 \mathrm{MPa}$ and $2000 \mathrm{MPa}$, along with shear traction ratios in the range of -0.4 to 0.4 were investigated for a varying crack size of 3 to $15 \mathrm{~mm}$. An interesting finding was that the crack tip opening displacements decreased while the crack tip sliding displacements increased with increasing crack length.
\end{abstract}

\footnotetext{
* To whom all correspondence should be addressed. E-mail: dcanadinc@ku.edu.tr.

$\dagger$ Current Affiliation: Koc University, Department of Mechanical Engineering, Istanbul, Turkey.
} 


\section{ACCEPTED MANUSCRIPT}

\section{Background and Motivation}

Extending the rail life has significant economic benefits to the railroad industry.

Currently, the concerns surrounding the rail are on the maintenance costs and increasing the margin of safety. Catastrophic rail failure can occur due to initiation of surface cracks at the railhead followed by their advance into the bulk of the rail. At a first glance, very low wear rates would be beneficial in rails, however, there are some advantages in controlled wear to curtail the fatigue cracks advancing in the rail head. We note that both wear and rolling contact fatigue (RCF) mechanisms operate simultaneously. As a result, an optimum wear rate (or grinding rate) under a given operating condition could extend the rail life [1] and mitigate catastrophic failure. The wear rates have been determined from laboratory experiments in the past and can be used to predict the field data, however, despite a significant body of work, a clear understanding of fatigue crack growth behavior under contact has not been established. Admittedly, this is a rather complex problem involving opening and sliding of crack surfaces, high closure forces under compression, and residual stress fields. Therefore, the present work focuses on simulation of all these factors that affect crack growth behavior.

As stated earlier, there have been numerous models proposed to predict the wear rates as a function of contact pressure, surface conditions and material hardness [2]. Although empirical, these models are sufficient to deliver the wear rate under various loading conditions. On the other hand, the prediction of fatigue crack growth rates under these conditions is rather complex and has not been explored fully. Previous attempts [3, 4] have been mostly focused on either fatigue crack initiation or determination of crack 


\section{ACCEPTED MANUSCRIPT}

driving forces under elastic contact. The excessive plastic deformation in rolling contact limits the use of linear-elastic fracture mechanics (LEFM) [5-15].

Generally, the fatigue cracks that initiate on free surfaces undergo both sliding and opening mode displacements (Stage I), and eventually turn to the plane of maximum tensile stress (Stage II) [11]. In RCF, however; cracks remain predominantly in Stage I due to the compressive stresses normal to the crack faces [12]. An added factor is the presence of external shear tractions that can produce a tensile stress, a Mode I crack opening, in addition to the Mode II sliding displacements. Our previous work on crack growth in Stage I (shear cracks) forms the basis for our simulations in this study [8]. We extend the work to determination of crack tip opening $\left(\Delta U_{I}\right)$ and crack tip sliding displacements $\left(\Delta U_{I I}\right)$ under repeated rolling contact.

There have been a number of investigations that focused on determining stress intensity levels for cracks subjected to RCF [13-15]. The $\Delta K_{I}$ (stress intensity factor range (SIF)) was shown to approach zero beyond a 'critical' crack length [13] which depends on the loading conditions and orientation of the crack [14]. In a recent study [15] focusing on the surface cracks under RCF, linear elastic finite element (FE) simulations were utilized to calculate the SIF ranges $\left(\Delta K_{I}\right.$ and $\left.\Delta K_{I I}\right)$ and a decrease in the SIF range occurred due to increasing friction between the crack faces upon crack advance. However, the previous studies performed to predict crack growth rates and fatigue life under RCF loading [16-17] were confined to elastic deformations. At the same time, the high wheel loads are generating deformation in the rail heads well beyond the elastic regime. It is known that the residual plastic deformation due to crack growth, and therefore the accumulated residual stresses [8] influence the crack growth behavior 


\section{ACCEPTED MANUSCRIPT}

drastically. To our knowledge, this is the first detailed investigation on the crack driving forces in half-plane contact accounting for elastic-plastic deformation history. We make a distinction between "static" and "propagating" cracks and show that allowing the crack "propagation" during the simulations produces a better description of the driving forces.

There are recent works focusing on predicting the rail life under rolling contact [1, 17, 18] recognizing the competition between the RCF and wear [17]. The elimination of surface crack by wear was forwarded as a strategy to improve rail life. But a minimum in the crack growth rate was predicted to be of the order of few microns, a rather small distance. Also, the fatigue crack growth simulations were not explicitly considered to ascertain the precise length which coincides with the minimum fatigue crack growth rate. This minimum (which we identify as several millimeters) depends non-trivially on the applied pressure, the friction between the crack surfaces, and the relative Mode I and Mode II components which are all analyzed in the present study.

As a result of the systematic analyses presented herein we postulate the following crack growth history. Initially small cracks propagate under RCF loading, however until a critical crack length is reached, the crack propagation rate decreases as the crack tip moves away from the contact stress field. At this critical crack length, the crack growth rate is at a minimum (Figure 1). Beyond this minimum point, however; crack propagation rate increases as the crack advances possibly because of the decrease in compressive closure forces. In the remainder of this paper, these differences and the basis for the proposed crack growth transients for a propagating crack are explained in detail in the light of extensive numerical simulations. 


\section{ACCEPTED MANUSCRIPT}

\section{Approach}

A detailed numerical investigation was carried out in which over $150 \mathrm{RCF}$ simulations were conducted. Each simulation required 2 hours of computational time on a 1.3GHz processor and was performed using an IBM pSeries 690 supercomputer. The FE mesh (using ABAQUS ) utilized over 25000 elements and a surface crack inclined $45^{\circ}$ to the half-plane (Figure 2). A $45^{\circ}$ inclination was selected because this orientation represents the plane of maximum shear stress range throughout the rolling contact (RC) cycle when a tangential force is applied [3]. The mesh is refined in the region where the crack faces are in contact, and at the crack tip. A typical element in the refined region (with fine mesh) is $0.5 \mathrm{~mm}$ wide and $0.2 \mathrm{~mm}$ tall with 4 nodes. However, smaller elements $0.25 \mathrm{~mm}$ wide and $0.1 \mathrm{~mm}$ tall were utilized along the crack faces and around the crack, such that 50 elements were placed along the crack length on each face of a $5 \mathrm{~mm}$ crack, and the plastic zone encompasses 10-20 elements around the crack tip (Figure 2). Since the contact area width is small in comparison to the curvature of the rail, the plane strain condition is utilized in the simulations. Both faces of the crack were defined as contact surfaces in the ABAQUS input file following the standard procedure, yet no special elements were utilized. Friction was also allowed in order to account for slip and stick between the faces of the crack. The coordinate system for the model, along with a schematic representation of the normal and shear loading, is shown in Figure 2 where 'e' is the distance between the load center and crack mouth, ' $a$ ' is the Hertzian half contact width, and $\mathrm{Q}$ and $\mathrm{P}$ are the tangential force and normal pressure distribution on the contact region. In the simulations, the load translates from the left to the right hand side of the mesh. The material studied in the FE simulations is a pearlitic rail steel. The 
material behavior is represented by kinematic hardening, and shear stress-shear strain data for the pearlitic steel under pure torsion of tubular specimens (obtained experimentally) is included in Figure 3. The fracture strain in shear is approximately 1.35 .

To model the semi-infinite elastic halfspace, infinite elements were implemented at the boundaries to ensure that a finite size mesh would provide reliable results [19-21]. The results from the FE model correlate well with a semi-analytical model for stresses developed by Jiang and Sehitoglu [4]. A schematic showing crack displacements and the coordinate systems used in this study is given in Figure 4. The dots on the crack faces represent nodal elements in the FE model that initially touch each other in the unloaded state [8]. In order to simulate rolling contact fatigue loading the Hertzian pressure is traversed across the half-plane, and the displacements are monitored every cycle. Under repeated rolling contact the crack opens and the crack faces slide relative to one another. The amount of opening is described by $U_{I}$ and the amount of relative sliding is denoted as $U_{I I}$. These variables are defined as

$\left.\begin{array}{l}U_{I}=U_{I, U P P E R}-U_{I, \text { LOWER }} \\ U_{I I}=U_{I I, U P P E R}-U_{I I, \text { LOWER }}\end{array}\right\}$

where UPPER and LOWER refer to the crack flanks.

Throughout the loading cycle, $U_{I}$ and $U_{I I}$ vary, and the ranges of $U_{I}$ and $U_{I I}$ are of utmost interest for determining crack driving force in fatigue. The total opening and sliding range throughout the loading cycle is defined as

$$
\left.\begin{array}{l}
\Delta U_{I}=U_{I-M A X}-U_{I-M I N} \\
\Delta U_{I I}=U_{I I-M A X}-U_{I I-M I N}
\end{array}\right\}
$$




\section{ACCEPTED MANUSCRIPT}

The $U_{I-M I N}$ equals zero since the crack tip is closed at some point throughout the loading cycle in every simulation, and $\Delta U_{I}$ and $U_{I-M A X}$ become equivalent. The maximum value of $U_{I I}$, referred to as $U_{I I-M A X}$, is obtained throughout the loading cycle, and similarly, $U_{I I-M I N}$ denotes the minimum value of $U_{I I}$ throughout the rolling $\mathrm{RC}$ cycle. By definition, $\Delta U_{I} \geq 0$ and $\Delta U_{I I} \geq 0$. The ranges of relative crack opening and sliding are of great importance as these values govern fatigue crack growth rates.

Depending on the loading conditions, the $\Delta U_{I}$ and the $\Delta U_{I I}$ can take on a variety of different values. The following definitions are implemented to describe the state of the crack [22]:

1. If $U_{I}>0$ at every point up to the crack tip (totally unzipped crack) the crack is said to be "fully open" (Figure 5). Alternatively, a crack is "closed" if $U_{I}=0$ at every node along the crack face. If $U_{I}$ is greater than zero at some nodes, and zero at others, the crack is described as "partially open".

2. If $U_{I I}$ is non-zero at any point along the crack face, the crack is said to have "partially slipped". However, if $U_{I I}$ is non-zero at every point up to the crack tip, the crack has "fully slipped". The crack is referred to as "sticking" if $U_{I I}$ does not change $\left(\Delta U_{I I}=0\right)$ during the loading cycle (Figure 6).

3. Forward slip will be defined when $U_{I I}$ increases, and reverse slip is implied by a decrease in the $U_{I I}$ (Figure 6).

Figures 5 and 6 display the concepts associated with crack opening and closure along with forward and reverse slip. Figure 5 shows the opening behavior for the crack tip of a $4.95 \mathrm{~mm}$ long crack subjected to a load with $\mathrm{p}_{0}=1500 \mathrm{MPa}$ and $\mathrm{Q} / \mathrm{P}=0.2$. A 
positive Q/P ratio implies that the tangential loading occurs in the same direction as rolling, as seen in Figure 2. The crack is closed, or $U_{I}=0$, for $\mathrm{Q} / \mathrm{P}=0.2$ until the load has passed over the crack mouth and is located at $\mathrm{e} / \mathrm{a} \approx 1.25$. The crack opening continues to increase until $\mathrm{e} / \mathrm{a} \approx 1.8$. The crack tip remains open even after the load has translated past the crack due to the residual stresses and plastic deformation built up around the crack tip during the loading cycle. The range of crack tip opening displacement throughout the loading cycle, $\Delta U_{I}$, is indicated on Figure 5.

Figure 6 displays the crack sliding behavior under pure rolling conditions $(\mathrm{Q} / \mathrm{P}=0)$. The crack has fully slipped throughout the entire loading cycle. As the load approaches the crack mouth and $e / a<-1.0$, reverse slip occurs, and the magnitude continues to increase as the load approaches the crack. As the load reaches e/a $\approx-1.0$, forward slip begins to occur. As the load passes over the crack mouth, sticking occurs as $U_{I I}$ remains constant. Both reverse and forward slip take place again as e/a $>0.5$ and the load travels away from the crack. As demonstrated by the pure rolling case, multiple regions of reverse and forward slip can occur during a single $\mathrm{RC}$ loading cycle. The definition of $\Delta U_{I I}$ for the entire loading pass is given schematically in Figure 6.

\section{Simulation Results}

Following the methodology outlined in the previous section, FE simulations were carried out systematically. First, the crack opening and sliding displacements of stationary cracks were calculated for varying Hertzian pressures and Q/P ratios. The analyses were then extended to propagating cracks, and the crack growth rates, along with the crack opening and sliding displacements, were calculated for different load-Q/P 


\section{ACCEPTED MANUSCRIPT}

ratio combinations. All FE simulations allowed for elastic-plastic deformation. In the remainder of this very section, the details of the calculations and the corresponding results are presented.

Opening and Sliding Behavior Under Different Shear Tractions

While the magnitude of crack tip opening and sliding vary with the applied load, general observations about crack behavior can be made depending on the direction of the tangential loading. The variation of $U_{I}$ and $U_{I I}$ at the crack tip can be seen in Figures 7 and 8 throughout a loading cycle for $\mathrm{Q} / \mathrm{P}=-0.2, \mathrm{Q} / \mathrm{P}=0$, and $\mathrm{Q} / \mathrm{P}=0.2$.

The crack opening behavior for a positive tangential load $(\mathrm{Q} / \mathrm{P}=0.2)$ was discussed in detail in the previous section, and it is compared to the opening behavior for different tangential loading in Figure 7. The crack opening behavior for negative tangential loading $(\mathrm{Q} / \mathrm{P}=-0.2)$ is much different than for either pure rolling or positive tangential loading. One interesting feature when $\mathrm{Q} / \mathrm{P}=-0.2$ is that the maximum crack tip opening occurs at $\mathrm{e} / \mathrm{a} \approx-1.5$, and the crack tip and crack faces are open before the loading reaches the crack mouth. Under a finite tangential force, residual $U_{I}$ persists after the load has translated past the crack. The crack opening displacements under pure rolling $(\mathrm{Q} / \mathrm{P}=0)$ with $\mathrm{p}_{0}=1500 \mathrm{MPa}$ are much different than those under finite tangential force since the crack tip never becomes open. For $\mathrm{Q} / \mathrm{P}=0$, the crack faces away from the crack tip open during the loading cycle; however, the crack tip remains closed throughout the entire loading cycle as seen in Figure 7. In other words, the crack becomes partially open under pure rolling. 


\section{ACCEPTED MANUSCRIPT}

The crack sliding behavior under pure rolling conditions was outlined in detail in the previous section, and is compared to finite $\mathrm{Q} / \mathrm{P}$ ratios in Figure 8 . Under a positive tangential load, reverse crack slip occurs almost immediately as $U_{I I}$ becomes negative. When the load approaches e/a $\approx-1.0$, forward slip takes place. As the load continues to pass over the crack mouth, the positive crack slip persists and $U_{I I}$ continues to increase until $\mathrm{e} / \mathrm{a} \approx 1.0$. The negative tangential force $(\mathrm{Q} / \mathrm{P}=-0.2)$ alters the crack sliding behavior drastically. The negative tangential load causes $U_{I I} \geq 0$ until $\mathrm{e} / \mathrm{a} \approx 0.5$, and the $U_{I I-M I N}$ occurs after the load has passed over the crack (e/a>0). For finite tangential loading, residual $U_{I I}$ persists and can be seen in Figure 8. For the resulting RC passes, these residual displacements represent the initial values for further deformation. Their presence affects the $\Delta U_{I I}$ in subsequent cycles and produces a distinction between 'propagating' and 'static' cracks.

\section{Static Cracks}

We first focus on the behavior of static cracks under contact loading. A static crack, also referred to as a "saw" crack, refers to a crack that is present without any residual plastic deformation from previous loading cycles. The plastic deformation history of the surrounding medium during the crack growth process has been ignored to reduce computational time and to preliminarily investigate the impact of different variables on crack tip displacements.

First, a crack of $4.95 \mathrm{~mm}$ in length was considered, with a coefficient of friction $\mu=0.1$ between the crack faces. Two different normal loads were applied with peak contact stresses of $\mathrm{p}_{0}=1500 \mathrm{MPa}$ and $\mathrm{p}_{0}=2000 \mathrm{MPa}$, and the $\mathrm{Q} / \mathrm{P}$ ratio was systematically 


\section{ACCEPTED MANUSCRIPT}

varied. The results for the maximum crack opening displacement can be found in Figure 9, and the range of crack tip sliding, $\Delta U_{I I}$, is presented as a function of the $\mathrm{Q} / \mathrm{P}$ ratio in Figure 10. The crack opening and sliding displacements both increase with increasing Q/P magnitude and higher normal loads. The ranges of crack tip opening and sliding are off-centered toward negative $\mathrm{Q} / \mathrm{P}$ values when $\mathrm{p}_{0}=2000 \mathrm{MPa}$. The loading condition of $\mathrm{p}_{0}=2000 \mathrm{MPa}$ produces significantly more plastic deformation than $\mathrm{p}_{0}==1500 \mathrm{MPa}$. Therefore, the residual stresses, and deformation at the crack tip that occur during the loading cycle lead to the offset of the $\Delta U_{I}$ and the $\Delta U_{I I}$ values for $\mathrm{p}_{0}=2000 \mathrm{MPa}$. The corresponding details of the plastic deformation are documented by Verzal [23].

Next, the combination of a normal load with a maximum Hertzian pressure of $\mathrm{p}_{0}=1500 \mathrm{MPa}$ and a $\mathrm{Q} / \mathrm{P}$ ratio of 0.2 was considered. Both the crack length and friction coefficients between the crack faces were varied. Even though the material on the crack faces remains the same, lubrication and surface roughness can change the coefficient of friction quite significantly, which can subsequently influence the behavior at the crack tip. During reverse slip when $e / a<0$, the normal force tends to reduce the contact pressure between the crack faces and minimizes the role of the friction coefficient. During forward slip when e/a $>0$, the normal force increases the contact force between the crack faces and maximizes the effect of friction. When the friction coefficient between the crack faces is low $(\mu \leq 0.2)$, the crack length and $U_{I I-M A X}$ increase proportionally (Figure 11). Nevertheless, as the friction coefficient between the crack faces becomes larger ( $\mu=0.35), U_{I I-M A X}$ decreases with increasing crack length. Longer cracks with high friction coefficients between the crack faces shield the crack tip from the applied stress field because the total frictional force along the crack face resisting slip is greater. 


\section{ACCEPTED MANUSCRIPT}

Frictional shielding of the crack tip can be illustrated by defining the crack sliding as a function of the distance from the crack tip (Figure 12). The coefficient of friction between the crack faces has a significant influence on the $U_{I I-M A X}$ profile along the crack face. When $\mu=0.3$, the crack tip is almost completely shielded from sliding and the slip profile becomes concave upward. Therefore, the $U_{I I-M A X}$ behavior as a function of crack length is the opposite for low coefficients of friction compared to high coefficients of friction.

When analyzing the effect of crack length on $\Delta U_{I I}$ (Figure 13), it can be clearly observed that the range of crack tip sliding increases as if it obeys a power law for low coefficients of friction, while remaining fairly constant for higher coefficients of friction. For high coefficients of friction, $U_{I I-M A X}$ decreases with increasing crack length while reverse slip increases since reverse slip is less dependent on the friction coefficient. Consequently, $\Delta U_{I I}$ remains fairly constant. In contrast, $U_{I I-M A X}$ and $U_{I I-M I N}$ both increase with increasing crack length for low friction coefficients between the crack faces, so $\Delta U_{I I}$ also increases with increasing crack length. Overall, as the coefficient of friction between the crack faces increases, the crack tip sliding displacements decrease.

Intuitively, the friction coefficient should not affect the $\Delta U_{I}$ since the crack faces are not in contact when the crack is open. However, a higher friction coefficient shields the crack tip which alters the profile of plastic zone at the crack tip. Consequently, the $\Delta U_{I}$ decreases as the friction between the crack faces increases (Figure 14). Most interestingly, the crack opening displacements also decrease as the crack length increases. The applied stress in the x-direction $\left(\sigma_{x}\right)$ is the main driver of crack opening, and $\sigma_{x}$ is 


\section{ACCEPTED MANUSCRIPT}

expressed as a function of depth into the material (Figure 15). It is shown for a variety of $\mathrm{Q} / \mathrm{P}$ ratios that $\sigma_{x}$ is two to three times larger at a depth of $3 \mathrm{~mm}$ than it is $8 \mathrm{~mm}$. Since $\sigma_{x}$ decays as the depth increases, the $\Delta U_{I}$ decreases as the crack length increases.

\section{Propagating Cracks}

All of the simulations in the previous section were concerned with static cracks, or cracks with no prior plastic deformation history. This simplification is not realistic because a residual stress field will accumulate due to the repeated RC loading, as well as around the crack tip, as the crack advances. In this section, the explanations regarding the analysis of propagating cracks are presented. In the corresponding FE simulations, a crack of $1=2.8 \mathrm{~mm}$ initial length was subjected to RCF until it grew to a length of $1=8.0 \mathrm{~mm}$. For some cases of particular interest, a modified mesh was used that allowed the crack to grow up to $15.0 \mathrm{~mm}$. The 'propagating crack' results were compared to the 'static crack' results to analyze the influence of the residual stress fields and residual displacements on the crack tip behavior. A detailed study was performed to determine the role of the point of release of the crack during the cycle, or the loading state at which the crack propagates. Within this analysis, the crack was advanced at $U_{I-M A X}, U_{I I-M A X}$, and $U_{I I-M I N} \cdot \Delta U_{I}$ and $\Delta U_{I I}$ were found to be independent from the point of release, and in the subsequent simulations the cracks were extended at the point of maximum positive slip, $U_{I I-M A X}[23]$.

As a result of the static crack analysis, it was found that $U_{I I-M A X}$ increases with crack length for low values of friction $(\mu \leq 0.2)$ and decreases with crack length for high values of friction, such as $\mu=0.35$ (Figure 11). However, for propagating cracks; 


\section{ACCEPTED MANUSCRIPT}

$U_{I I-M A X}$ decreases when subjected to a load with $\mathrm{p}_{0}=2000 \mathrm{MPa}$ and $\mathrm{Q} / \mathrm{P}=0.2$, with a friction coefficient of 0.2 between the crack faces (Figure 16). A comparison of the range of crack tip sliding, $\Delta U_{I I}$, between the static and propagating cracks for friction coefficients of 0.1 and 0.2 is presented in Figure 17 for the same loading conditions. The range of crack tip sliding is smaller for propagating cracks than for static cracks.

\section{Crack Growth Rates}

The simplest model for predicting mixed mode crack growth rates is an additive model based on the type of loading experienced by the crack [11]. For a plane strain RC surface crack, Mode I and Mode II loading occurs, and the crack growth rate can be defined as

$\frac{d a}{d N}=C_{3}\left(\Delta K_{I}\right)^{m_{3}}+C_{4}\left(\Delta K_{I I}\right)^{m_{4}}$

where $C_{3}, C_{4}, m_{3}$, and $m_{4}$ are empirically determined constants. If the crack tip displacements are used [24], the crack growth rate can be defined as

$\frac{d a}{d N}=C_{1}\left(\Delta U_{I}\right)^{m_{1}}+C_{2}\left(\Delta U_{I I}\right)^{m_{2}}$

where $C_{1}, C_{2}, m_{1}$, and $m_{2}$ are empirical constants (Figure 18); however different than those present in Equation 3. The determination of the constants applicable to RCF crack propagation requires a significant amount of experimental effort, which is beyond the scope of this very paper. Consequently, the crack growth rates will be normalized in this study in the following manner

$\left(\frac{d a}{d N}\right) / C_{1}=\left(\Delta U_{I}\right)^{m_{1}}+\frac{C_{2}}{C_{1}}\left(\Delta U_{I I}\right)^{m_{2}}$ 


\section{ACCEPTED MANUSCRIPT}

If the crack growth equation is applied to the $\mathrm{RC}$ behavior for propagating cracks, the crack growth rate as a function of crack length can be derived for a surface crack under RC loading.

In order to investigate typical crack growth rates, first a propagating crack subjected to a normal load of $\mathrm{p}_{0}=1500 \mathrm{MPa}$ with $\mathrm{Q} / \mathrm{P}=0.2$ and a friction coefficient of 0.2 between the crack faces was considered. For this simulation, a modified mesh was implemented allowing crack tip displacements to be calculated from $3 \mathrm{~mm}$ to $15 \mathrm{~mm}$. The crack growth rate as a function of crack length was calculated for three different values of the constant $C_{2} / C_{1}$, with $\mathrm{m}_{1}=\mathrm{m}_{2}=2$ (Figure 19). When investigating the crack tip displacements from the FE model, the $\Delta U_{I}$ was found to decrease with increasing crack length while the $\Delta U_{I I}$ increased. Additionally, Equation 5 contains a component of crack growth due to Mode I loading and another component due to Mode II loading. Consequently, the crack growth rate due to Mode I loading decreases as the crack length increases, whereas the crack propagation rate due to Mode II deformation increases with crack length. Since one component of the growth rate is increasing while the other is decreasing with increasing crack length, a minimum exists on the total crack growth curve. As $C_{2} / C_{1}$ decreases, the crack growth caused by $\Delta U_{I I}$ decreases relative to $\Delta U_{I}$, and the minimum point in the crack growth rate function shifts toward longer crack lengths. A minimum does not exist between $3 \mathrm{~mm}$ and $12 \mathrm{~mm}$ when $C_{2} / C_{1}=0.1$ because Mode II crack growth is already dominating at $3 \mathrm{~mm}$. For this case, the minimum is expected at a crack length shorter than $3 \mathrm{~mm}$.

Figure 20 displays a comparison of the crack growth rate for Hertzian contact loads with a peak stresses of $\mathrm{p}_{0}=1500 \mathrm{MPa}$ and $\mathrm{p}_{0}=2000 \mathrm{MPa}$. For these simulations, the 


\section{ACCEPTED MANUSCRIPT}

$\mathrm{Q} / \mathrm{P}$ ratio was 0.2 and a friction coefficient was varied. The constants implemented for the crack growth model were $C_{2} / C_{1}=0.01$ and $m_{1}=m_{2}=2$. The most obvious feature of this graph is the difference in crack growth rate magnitudes between the two loading scenarios. The crack growth rate for $\mathrm{p}_{0}=2000 \mathrm{MPa}$ is almost an order of magnitude larger than the propagation rate for $\mathrm{p}_{0}=1500 \mathrm{MPa}$. An interesting feature is the location of the minimum. The minimum for $\mathrm{p}_{0}=2000 \mathrm{MPa}$ occurs at a crack length of approximately $4 \mathrm{~mm}$ where the $\mathrm{p}_{0}=1500 \mathrm{MPa}$ load reaches a minimum around $7-8 \mathrm{~mm}$. When $\mathrm{p}_{0}=2000$ $\mathrm{MPa}$, the $\Delta U_{I I}$ displacement increases with crack length. However, the $\Delta U_{I}$ displacements decrease very gradually and the minimum of the function occurs at a shorter crack lengths. When $\mathrm{p}_{0}=1500 \mathrm{MPa}, \Delta U_{I}$ displacements typically decrease significantly when the crack length is longer than $5 \mathrm{~mm}$ while the $\Delta U_{I I}$ displacements increase gradually. Therefore, the minimum of the overall growth rate function is reached after the large decrease in opening displacements. If the opening displacements for $\mathrm{p}_{0}=2000 \mathrm{MPa}$ decrease significantly for cracks longer than the ones considered in this study, it is possible that another minimum in the overall growth rate function could exist at crack lengths longer than $10.0 \mathrm{~mm}$.

The crack growth rates can also be analyzed depending on the coefficient of friction $(\mu)$ between the crack faces. As expected, the crack growth rates decrease as $\mu$ increases because the higher frictional force reduces $\Delta U_{I}$ and $\Delta U_{I I}$. When $\mathrm{p}_{0}=1500$ $\mathrm{MPa}$, it can be seen that the trends in the crack growth rate change when $\mu=0.35$. When $\mu=0.1$ or $\mu=0.2$, the $\Delta U_{I I}$ displacements make a significant contribution to the crack growth rate. When $\mu=0.35$, the $\Delta U_{I}$ displacements dominate the crack growth rate for crack lengths between $3 \mathrm{~mm}$ and $10 \mathrm{~mm}$ due to the drastic reduction in sliding 


\section{ACCEPTED MANUSCRIPT}

displacement. Therefore, the crack growth rate for $\mu=0.35$ decreases gradually as the crack tip opening displacements decrease. It is expected that a minimum would occur in the crack growth function for $\mu=0.35$ as the crack becomes long enough, such that the $\Delta U_{I}$ displacements approach 0.

\section{Discussion and Final Remarks}

\section{Crack Propagation}

Propagating cracks generate an evolving plastic zone around the crack tip and residual displacements along the crack faces as the crack advances. The residual displacements in the wake of the crack tip lead to smaller crack tip displacements when comparing a propagating crack to a static crack under identical loading $[8,25]$. The role of the plastic zone generated by a fatigue (propagating) crack was previously investigated, and a comparison of crack opening displacements from a fatigue crack to those from a stationary (static) crack was presented [25]. Accordingly, under uniaxial loading, the crack tip opening displacement was found to be lower than the static displacements at the crack tip and along the crack faces, due to residual displacements. The current study revealed that, for propagating cracks released at $U_{I I-M A X}$, a residual compressive stress exists at the crack tip due to the residual displacements. Consequently, the friction between the crack faces increases and the relative sliding decreases. For instance, for $\mathrm{p}_{0}=2000 \mathrm{MPa}$ and $\mathrm{Q} / \mathrm{P}=0.2$ with a friction coefficient of 0.2 between the crack faces, the magnitude of $U_{I I-M A X}$, the maximum relative sliding between the faces of a propagating crack, is much smaller as compared with that in the case of a static crack (Figure 16). Additionally, the increased friction stemming from the compressive residual 
stress field brings about a decrease in both $\Delta U_{I}$ (Figure 14) and $\Delta U_{I I}$ (Figure 17). These observations stand in good agreement with the findings of our previous work $[8,25]$.

We note that, in the present investigation, a minimum in the $d a / d N$ curve exists due to a competition between Mode I and Mode II displacements as the crack grows. Previous works $[1,18]$ attributed the origin of such a minimum to the decay in contact stress field and increased bending stresses. On the contrary, the present work postulates that the minimum depends entirely on the relative contributions from $\Delta U_{I}$ and $\Delta U_{I I}$ due to the applied contact stress, which changes with increasing crack length. For instance, for the case of $\mathrm{p}_{0}=1500 \mathrm{MPa}, \Delta U_{I}$ displacements were observed to decrease significantly (Figure 14) when the crack length is longer than $5 \mathrm{~mm}$, while the $\Delta U_{I I}$ displacements increased gradually (Figure 13). As a result, the minimum of the overall crack growth rate function was attained after the large decrease in opening displacements (Figures 19 and 20). Since bending stresses are not considered in the current simulations, the interplay between $\Delta U_{I}$ and $\Delta U_{I I}$ is sufficient to explain the minimum.

\section{Competition Between Wear and Crack Propagation}

The current results demonstrated that, although both crack propagation due to RCF and wear lead to rail failure, an optimum combination of these two mechanisms may yield a prolonged rail life. Specifically, a crack propagation rate that is greater than the wear rate leads to rail failure due to crack propagation. However, if the wear rate is greater, then the crack will be worn away before reaching a critical length, yet wear will be the mechanism responsible for rail deterioration, and ultimately adverse changes in the rail contour. This would cause severe contact at rail corners and affect the performance of 
the rail vehicle. Nevertheless, an optimum combination of wear and crack growth rates could be of significant benefit in curtailing rail failure. Namely, wear at the crack mouth could limit the crack length to avoid rapid crack growth. These cracks could eventually lead to branching and catastrophic failure. The crack growth rate itself depends on the crack opening and sliding displacements, and thus the crack length and the minimum point of a crack growth rate function are of crucial importance in optimizing the competition between the rates of crack propagation and wear.

To demonstrate this argument, wear experiments were carried out at the University of Sheffield to experimentally determine the wear rates for various Hertzian contact peak pressures [26]. Disc-on-disc tests were conducted to simulate the RC between rail and wheel, and the disc materials were chosen accordingly. Wear rates were determined by monitoring the weight loss and dimensional changes in each disc. Some of the results from these wear tests are compared to the crack growth rates obtained from the current simulations, further emphasizing the importance of the knowledge of the minimum crack growth rate and the corresponding crack length (Figures 21 and 22). For instance, for a propagating crack that advanced to $8 \mathrm{~mm}$ in length under a Hertzian contact load with a peak pressure of $\mathrm{p}_{0}=2000 \mathrm{MPa}$, for a friction coefficient of 0.1 between the crack faces, the normalized wear rate $\left(3 \times 10^{-7} \mathrm{~mm} /\right.$ cycle, assuming $\left.C_{l}=1\right)$ is considerably lower than the normalized crack propagation rate $\left(6 \times 10^{-5} \mathrm{~mm} / \mathrm{cycle}\right.$, assuming $C_{l}=1$ ) (Figure 22), implying that the rail failure will take place due to rapid growth of initially small surface cracks.

We note that the presentation of the crack growth rate $(d a / d N)$ data (Figures 1922) in a normalized fashion (with respect to $C_{l}$ ) is not coincidental. The reason is that the 
empirical constants $C_{1}$ and $C_{2}$ are not available, and further experimental effort is needed in order to establish these values for the RCF case. However, this is beyond the scope of the current work. Moreover, normalization allows the assumption of any values for the $C_{1}$ and $C_{2}$, and therefore enables the observation of trends in general for various possible scenarios.

Previously, the life cycle of a crack was described as a four-stage phenomenon [1, 18]: Crack initiation by low-cycle fatigue (LCF), ratcheting damage and early crack growth are followed by lengthening of the crack, leading to higher stress concentrations, and therefore higher crack propagation rates. Beyond a critical crack length, the tip of the crack moves away from the contact stress field, resulting in a reduction of the crack growth rate. However, once the crack is sufficiently long, bending stresses lead to rail failure [1, 18]. Nevertheless, the results of the current study depict an alternative scenario: Initially small cracks propagate due to repeated RC loading, yet the crack propagation rate decreases as the crack tip moves away from the contact stress field (it should be noted that the current work does not consider crack initiation by LCF). Once a critical crack length is reached, the crack growth rate assumes its minimum (Figure 1). Beyond this minimum point, however; crack propagation rate increases concomitant with the increasing crack length. In fact, the current simulation results support that $\Delta U_{I}$ decreases with increasing crack length for all coefficients of friction (Figure 14) whereas an increase in $\Delta U_{I I}$ is evident as the crack length increases (Figure 13). Since the crack growth rate $(d a / d N)$ is a function of both $\Delta U_{I}$ and $\Delta U_{I I}$ (Equation 4), crack growth rate history similar to the one illustrated in Figure 1 is expected for a propagating crack. For a 


\section{ACCEPTED MANUSCRIPT}

given friction coefficient between the crack faces, the minimum crack growth rate can assume different values, which is dictated by $\mathrm{p}_{0}$ and $C_{2} / C_{1}$ ratio (Figures $19-22$ ).

\section{On the Simulations}

It was earlier demonstrated that the crack mouth will open but the crack tip will remain closed for a surface crack in an elastic half-space under pure rolling Hertzian contact loading, for any given peak pressure [14]. Nontheless, our analyses pointed out that the validity of this statement strongly depends on the peak pressures; the crack tip remains closed under pure rolling Hertzian contact loading for $\mathrm{p}_{0}=1500 \mathrm{MPa}$, whereas significant plastic deformation and crack tip opening displacements are present for the case of $\mathrm{p}_{0}=2000 \mathrm{MPa}$ (Figure 9). We note that the disagreement between the results of Fujimoto et al. [14] and the current findings stems mainly from the different material models and crack advance procedure. Specifically, both static and propagating cracks of lengths in the $2-5 \mathrm{~mm}$ range were investigated, where the propagating cracks were allowed to grow to $8 \mathrm{~mm}$, and $15 \mathrm{~mm}$ in specific cases, which are much larger than the microstructural features that are known to affect the crack growth, such as pearlite spacing and pearlite colony size. Furthermore, this is the regime where "continuum" analysis provides reliable results. Such crack length necessitates the consideration of EPFM -as done in the current paper- since the crack is short, and the plastic zone size to crack length ratio is large, where the crack growth is elastic-plastic in nature. Two recent works utilizing the concept of EPFM in the analysis of crack growth [18, 27] considered extremely short cracks, where the crack lengths varied between $0.05-0.4 \mathrm{~mm}$. In our case, we would not find a minimum in this range. We note that the crack lengths utilized 
in the current study are an order of magnitude greater. Accordingly, most surface cracks of critical length in the railheads fall into the range of $2-5 \mathrm{~mm}$, and usually possess an angle of about $45^{\circ}$ with the contact surface for the material considered.

\section{Conclusions}

Based on the work presented herein, we draw the following conclusions:

1. Normalized crack growth rates as a function of crack length display a minimum because $\Delta U_{I}$ decreases with crack length while $\Delta U_{I I}$ increases with crack length. The previous works have predicted the existence of a minimum in the $d a / d N$ function with respect to crack length, and attributed the minimum to decaying contact stress fields and increasing bending stress fields. In the present study, we demonstrated that higher normal loads lead to higher crack propagation rates, while higher friction coefficients between the crack surfaces decrease the crack growth rate.

2. Propagating cracks generate a plastic deformation history around the crack faces and the crack tip. Consequently, the magnitudes of $\Delta U_{I}$ and $\Delta U_{I I}$ are lower for a propagating crack when compared to a static crack. The results also point toward different crack tip sliding trends with increasing crack length between static and propagating cracks.

3. The friction coefficient between the crack faces can drastically alter the sliding displacements experienced by the crack tip. As the friction coefficient approaches 0.35, the frictional forces shield the crack tip from the stress field and the $U_{I I-M A X}$ decreases with increasing crack length. Consequently, the range of crack tip sliding remains nearly constant with increasing crack length when the friction coefficient is 0.35 


\section{ACCEPTED MANUSCRIPT}

while sliding displacements increase with increasing crack length for lower friction coefficients.

4. The magnitude and direction of tangential loading can significantly alter the opening and sliding behavior at the crack tip of a $45^{\circ}$ surface crack during a rolling contact (RC) cycle. Unlike elastic analysis, the results indicate that crack tip opening displacements can occur under pure rolling $(\mathrm{Q} / \mathrm{P}=0)$ contact conditions if the applied load causes plastic deformation.

5. From a design point of view, the knowledge of crack growth rate as a function of crack length is of crucial importance. An optimum combination of crack propagation and wear rates is expected to yield a prolonged rail life.

\section{Acknowledgments}

This study was funded by Transportation Technology Center, Inc. (TTCI), a subdivision of Association of American Railroads (AAR). The numerical simulations were carried out on an IBM pSeries 690 supercomputer at the National Center for Supercomputing Applications (NCSA), University of Illinois at Urbana-Champaign. The wear test results used in this study were obtained at the University of Sheffield, United Kingdom.

\section{References}

[1] Kapoor A. Wear Fatigue Interaction and Maintenance Strategies. Unpublished technical report 2003. 


\section{ACCEPTED MANUSCRIPT}

[2] Archard JF, Hirst W. Wear of meals under unlubricated conditions. Proc Roy Soc Lond A1956; Vol. 236, No. 1206, p. 397-410.

[3] Jiang Y, Sehitoglu H. Cyclic Stresses for Contact with Different Tangential Load Distributions. Technical Report submitted to American Association of Railroads 1991.

[4] Jiang Y, Sehitoglu H. A Model for Rolling Contact Failure. Wear 1999;224:38-49.

[5] Bold PE, Brown MW, Allen RJ. A Review of Fatigue Crack Growth in Steels under Mixed Mode I and II Loading. Fatigue Fract Engng Mater Struct 1992; Vol. 15, No. 10:965-977.

[6] Gao Hua, Alagok N, Brown MW, Miller KJ. Growth of Fatigue Cracks under Combined Mode I and II Loads. Multiaxial Fatigue, ASTM STP 853, American Society for Testing and Materials 1985, Philadelphia Pa., p. 184-202.

[7] Smith EW, Pascoe KJ. Fatigue Crack Initiation and Growth in a High Strength Ductile Steel Subject to in Plane Biaxial Loading. Multiaxial Fatigue, ASTM STP 853, American Society for Testing and Materials 1985, Philadelphia Pa., p. 111-134.

[8] Kibey S, Sehitoglu H, Pecknold DA. Modeling of Fatigue Crack Closure in Inclined and Deflected Cracks. International Journal of Fracture 2004; Vol. 129, No. 3:279308.

[9] Otsuka A, Mori K, Miyata T. The Condition of Fatigue Crack Growth in Mixed Mode Condition. Engineering Fracture Mechanics 1975;7:429-439.

[10] Bold PE, Brown MW, Allen RJ. Shear Mode Crack Growth and Rolling Contact Fatigue. Wear 1991;144:307-317. 


\section{ACCEPTED MANUSCRIPT}

[11] Liu HW. Shear Fatigue Crack Growth: A Literature Survey. Fatigue Fract Engng Mater Struct 1985; Vol. 8, No. 4:295-313.

[12] Hahn GT, Bhargava V, Yoshimura H, and Rubin C. Analysis of Rolling Contact Fatigue and Fracture. Advances in Fracture Research, Proceedings from the $6^{\text {th }}$ International Conference on Fracture, New Delhi Ind. 1984. p. 295-316.

[13] Keer LM, Bryant MD, Haritos GK. Subsurface and Surface Cracking due to Hertzian Contact. Journal of Lubrication Technology 1982;104:347-351.

[14] Fujimoto K, Yoshikawa Y, and Shioya T. Opening Behavior of a Surface Crack in an Elastic Half-plane under Hertzian Contact Loading. Contact Mechanics III, International Conference on Contact Mechanics, Madrid, Spain, Vol. $3^{\text {rd }}$ International Conference, July 1997. p. 139-148.

[15] Benuzzi D, Bormetti E, Donzella G. Stress Intensity Factor Range and Propagation Mode of Surface Cracks under Rolling-Sliding Contact. Theoretical and Applied Fracture Mechanics 2003;40:55-74.

[16] Keer LM, Bryant MD. A Pitting Model for Rolling Contact Fatigue. Transactions of the ASME 1983;105:198-205.

[17] Donzella G, Faccoli M, Ghidini A, Mazzù A, Roberti R. The Competitive Role of Wear and RCF in a Rail Steel. Engineering Fracture Mechanics 2005;72:287-308.

[18] Ringsberg JW. Shear Mode Growth of Short Surface-Breaking RCF Cracks. Wear $2005 ; 258: 955-963$.

[19] Bhargava V, Hahn GT, Rubin CA. An Elastic-Plastic Finite Element Model of Rolling Contact, Part 1: Analysis of Single Contacts. Journal of Applied Mechanics $1985 ; 52: 67-74$. 


\section{ACCEPTED MANUSCRIPT}

[20] Balzer M, Sehitoglu H, and Moyar G. An Inelastic Finite Element Analysis of the Contribution of Rail Chill to Braked Tread Surface Fatigue. RTD, Rail Transportation, ASME 1992;5:117-122.

[21] Zienkiewicz OC, Emson C, Bettess P. A Novel Boundary Infinite Element. International Journal for Numerical Methods in Engineering 1983;19:393-404.

[22] Smith MC, Smith RA. Towards an Understanding of Mode II Fatigue Crack Growth. Basic Questions in Fatigue: Volume 1, ASTM STP 924, J.T. Fong and R.J. Fields, Eds., American Society for Testing and Materials, Philadelphia, 1988;1:260-280.

[23] Verzal KE. Surface Crack Behavior under Rolling Contact Loading: Initiation and Propagation. MS Thesis, Materials Engineering - Mechanical Behavior, College of Engineering, University of Illinois at Urbana-Champaign. May 2005.

[24] Kanninen MF, Popelar CH. Advanced Fracture Mechanics. New York: Oxford University Press; 1985.

[25] McClung RC, Sehitoglu H. On the Finite Element Analysis of Fatigue Crack Closure-2. Numerical Results. Engineering Fracture Mechanics 1989; Vol. 33, No. 2:253-272.

[26] Alwahdi F, Franklin F, Kapoor A. Unpublished technical report 2003.

[27] Ishihara S, McEvily AJ. Analysis of Short Fatigue Crack Growth in Cast Aluminum Alloys. International Journal of Fatigue 2002;24:1169-1174. 


\section{ACCEPTED MANUSCRIPT}

\section{Figure Captions:}

Figure 1. Schematic illustrating the life cycle of a crack; and the competition between crack growth rate and wear rate.

Figure 2. Coordinate systems and load definition associated with crack behavior simulations, and the finite element mesh model with a close-up view of the crack-tip area. For $\mathrm{p}_{0}=1500 \mathrm{MPa}, \mathrm{a}=13.9 \mathrm{~mm}$; and for $\mathrm{p}_{0}=2000 \mathrm{MPa}, \mathrm{a}=18.6 \mathrm{~mm}$.

Figure 3. Shear stress-shear strain data for pearlitic rail steel from a pure torsion test to fracture.

Figure 4. Schematic illustrating the $U_{I}$ and the $U_{I I}$ displacements on the crack face.

Figure 5. Schematic illustrating open and closed cracks throughout the loading cycle for loading corresponding to $\mathrm{p}_{0}=1500 \mathrm{MPa}, \mathrm{Q} / \mathrm{P}=0.2, \mu=0.1$, and a crack of length $4.95 \mathrm{~mm}$ for a static crack.

Figure 6. Schematic illustrating forward and reverse slip throughout the loading cycle for loading corresponding to $\mathrm{p}_{0}=1500 \mathrm{MPa}, \mathrm{Q} / \mathrm{P}=0, \mu=0.1$, and a crack of length $4.95 \mathrm{~mm}$ for a static crack.

Figure 7. Variation of the crack tip opening displacement throughout the loading cycle for different values of $\mathrm{Q} / \mathrm{P}$. The simulations use a Hertzian peak stress of $\mathrm{p}_{0}=1500 \mathrm{MPa}$ and a static crack of length $4.95 \mathrm{~mm}$ with a coefficient of friction between the crack faces of 0.1

Figure 8. Variation of the crack tip sliding displacement throughout the loading cycle for different values of $\mathrm{Q} / \mathrm{P}$. The simulations use a Hertzian peak stress of $\mathrm{p}_{0}=1500 \mathrm{MPa}$ and a static crack of length $4.95 \mathrm{~mm}$ with a coefficient of friction between the crack faces of 0.1 . 


\section{ACCEPTED MANUSCRIPT}

Figure 9. Crack tip opening displacements versus Q/P ratio for Hertzian contact loads with peak pressures of $\mathrm{p}_{0}=1500 \mathrm{MPa}$ and $\mathrm{p}_{0}=2000 \mathrm{MPa}$. The data is for a static crack of length $4.95 \mathrm{~mm}$ and a friction coefficient of 0.1 between the crack faces.

Figure 10. Crack tip sliding displacements versus $Q / P$ for a Hertzian contact with peak loads of $\mathrm{p}_{0}=1500 \mathrm{MPa}$ and $\mathrm{p}_{0}=2000 \mathrm{MPa}$. The data is for a static crack of length $4.95 \mathrm{~mm}$ and a friction coefficient of 0.1 between the crack faces.

Figure 11. $U_{I I-M A X}$ versus crack length plotted for different coefficients of friction. A Hertzian load with $\mathrm{p}_{0}=1500 \mathrm{MPa}$ and $\mathrm{Q} / \mathrm{P}=0.2$ was applied to static cracks.

Figure 12. $U_{I I-M A X}$ as a function of the distance from the crack tip for a $5 \mathrm{~mm}$ static surface crack for different coefficients of friction. A Hertzian load with $\mathrm{p}_{0}=1500 \mathrm{MPa}$ and a $\mathrm{Q} / \mathrm{P}$ ratio of 0.2 was applied.

Figure 13. $\Delta U_{I I}$ versus crack length plotted for different coefficients of friction. A Hertzian load with $\mathrm{p}_{0}=1500 \mathrm{MPa}$ and $\mathrm{Q} / \mathrm{P}=0.2$ was applied to static cracks.

Figure 14. $\Delta U_{I}$ versus static crack length plotted for different coefficients of friction. A Hertzian load with $\mathrm{p}_{0}=1500 \mathrm{MPa}$ and $\mathrm{Q} / \mathrm{P}=0.2$ was applied.

Figure 15. Depth versus $\sigma_{x}$ for different values of tangential loading under a Hertzian normal load with $\mathrm{p}_{0}=1500 \mathrm{MPa}$. The intermediate data lines correspond to $\mathrm{Q} / \mathrm{P}=0.3$ and $\mathrm{Q} / \mathrm{P}=0.2$.

Figure 16. $U_{I I-M A X}$ and $U_{I I-M I N}$ versus crack length for propagating and static cracks with a friction coefficient of 0.2 when subjected to a load of $\mathrm{p}_{0}=2000 \mathrm{MPa}$ and $\mathrm{Q} / \mathrm{P}=0.2$.

Figure 17. Comparison of crack tip sliding displacements for propagating and static cracks subjected to a load of $\mathrm{p}_{0}=2000 \mathrm{MPa}$ and $\mathrm{Q} / \mathrm{P}=0.2$.

Figure 18. Schematic defining the empirical constants of Equations 4 and 5. 
Figure 19. Normalized crack growth rate for different ratios of $C_{2} / C_{1}$ when $m_{1}=m_{2}=2$. The propagating crack simulations were conducted with a peak Hertzian load of $\mathrm{p}_{0}=1500$ $\mathrm{MPa}, \mathrm{Q} / \mathrm{P}=0.2$, and a friction coefficient of 0.2 between the crack faces.

Figure 20. Normalized crack growth rate for different values of the Hertzian peak contact stress. For the propagating crack simulations, $\mathrm{Q} / \mathrm{P}=0.2, m_{1}=m_{2}=2$, and $C_{2} / C_{1}=0.01$.

Figure 21. Comparison of normalized wear rates (dashed lines), and normalized crack growth rates of Figure 19.

Figure 22. Comparison of normalized wear rates (dashed lines), and normalized crack growth rates of Figure 20. 
Figure-1

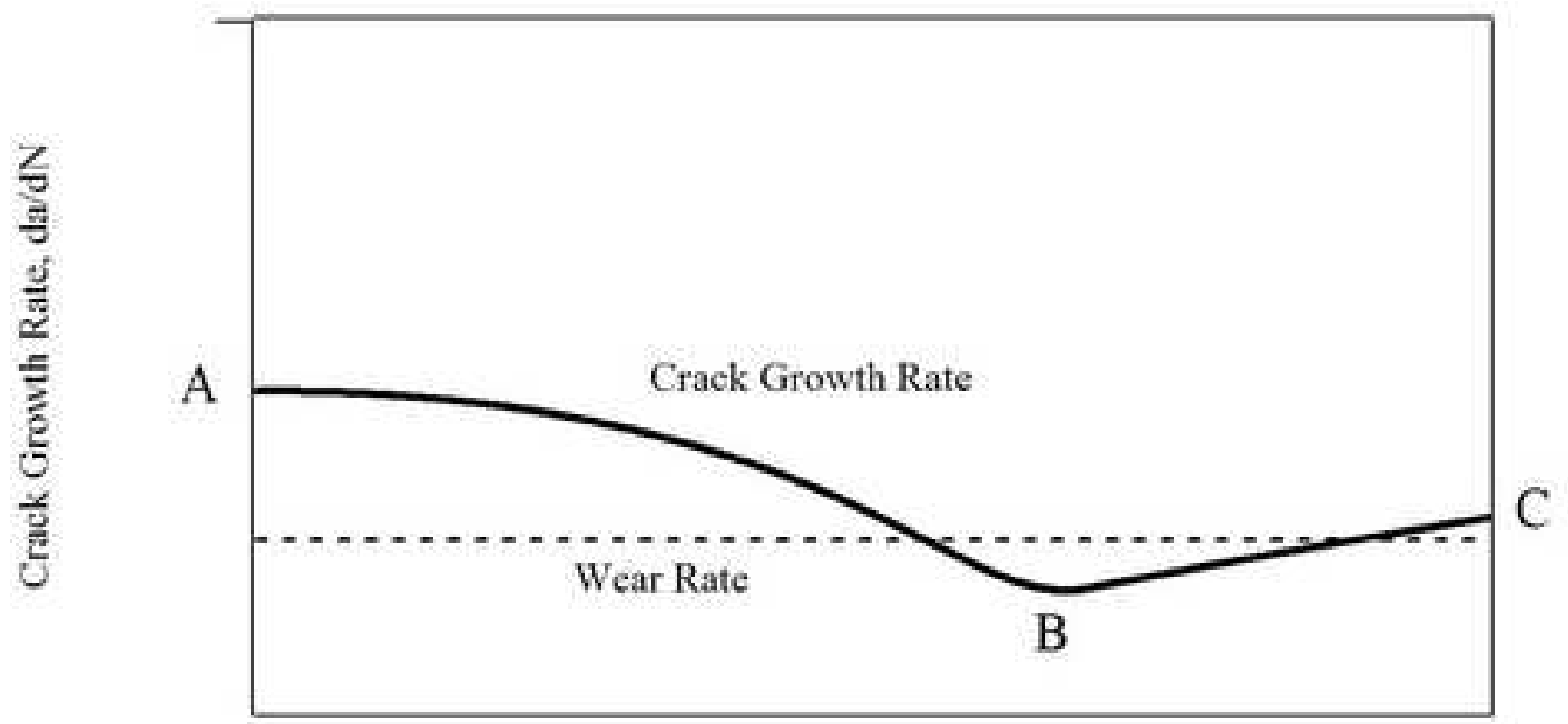

Crack Length, a 
Figure-2
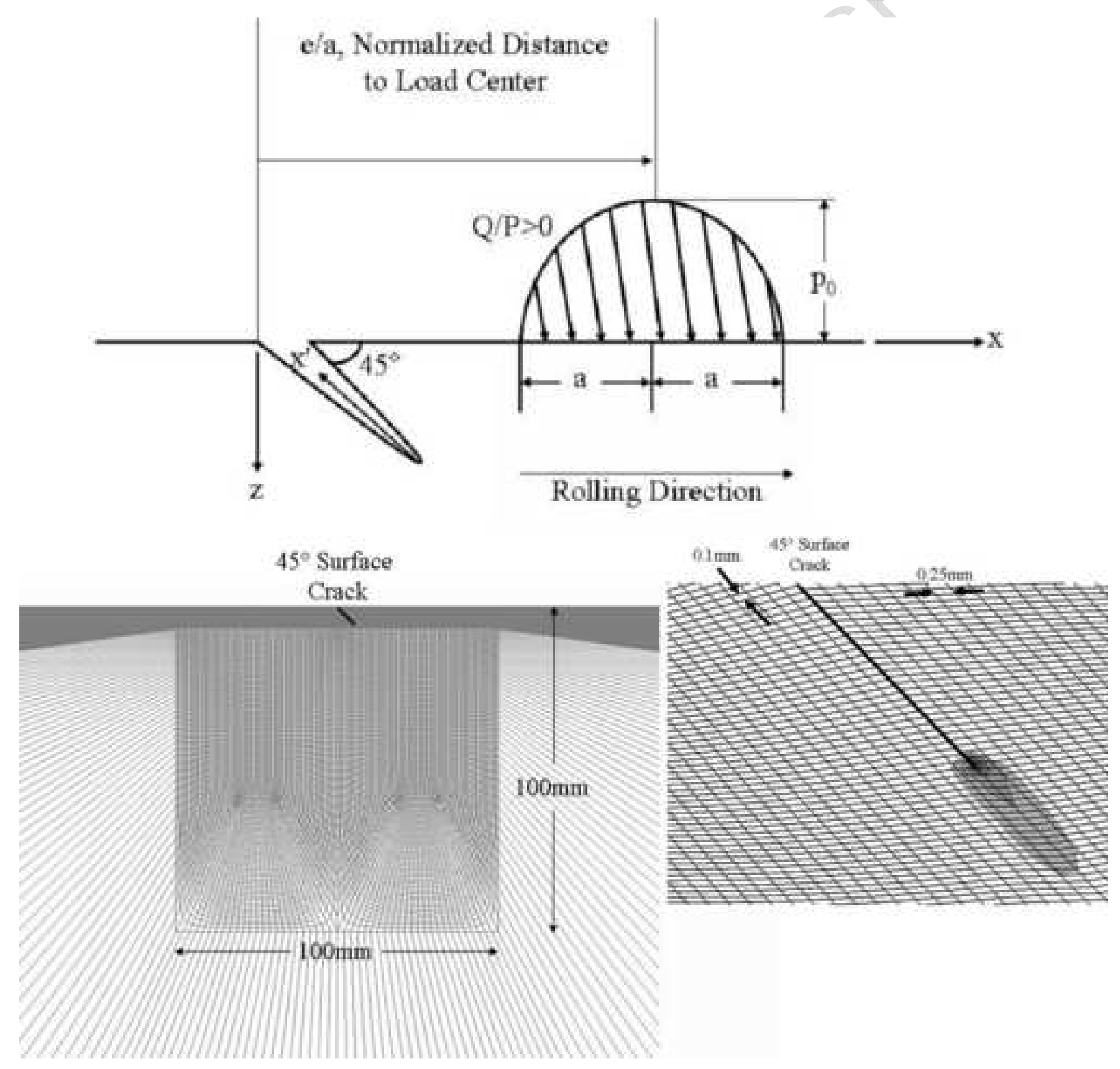
Figure-3

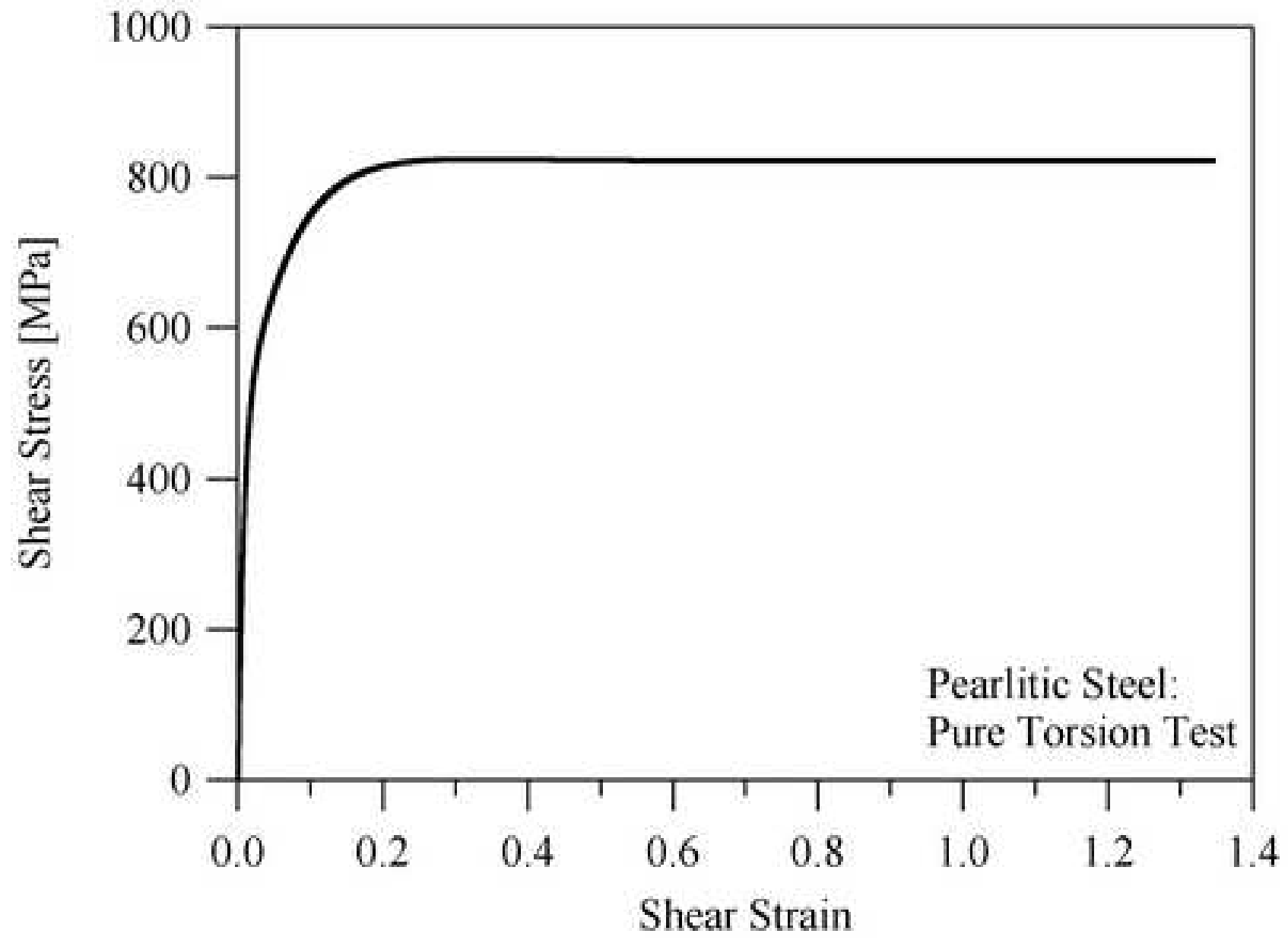


Figure-4

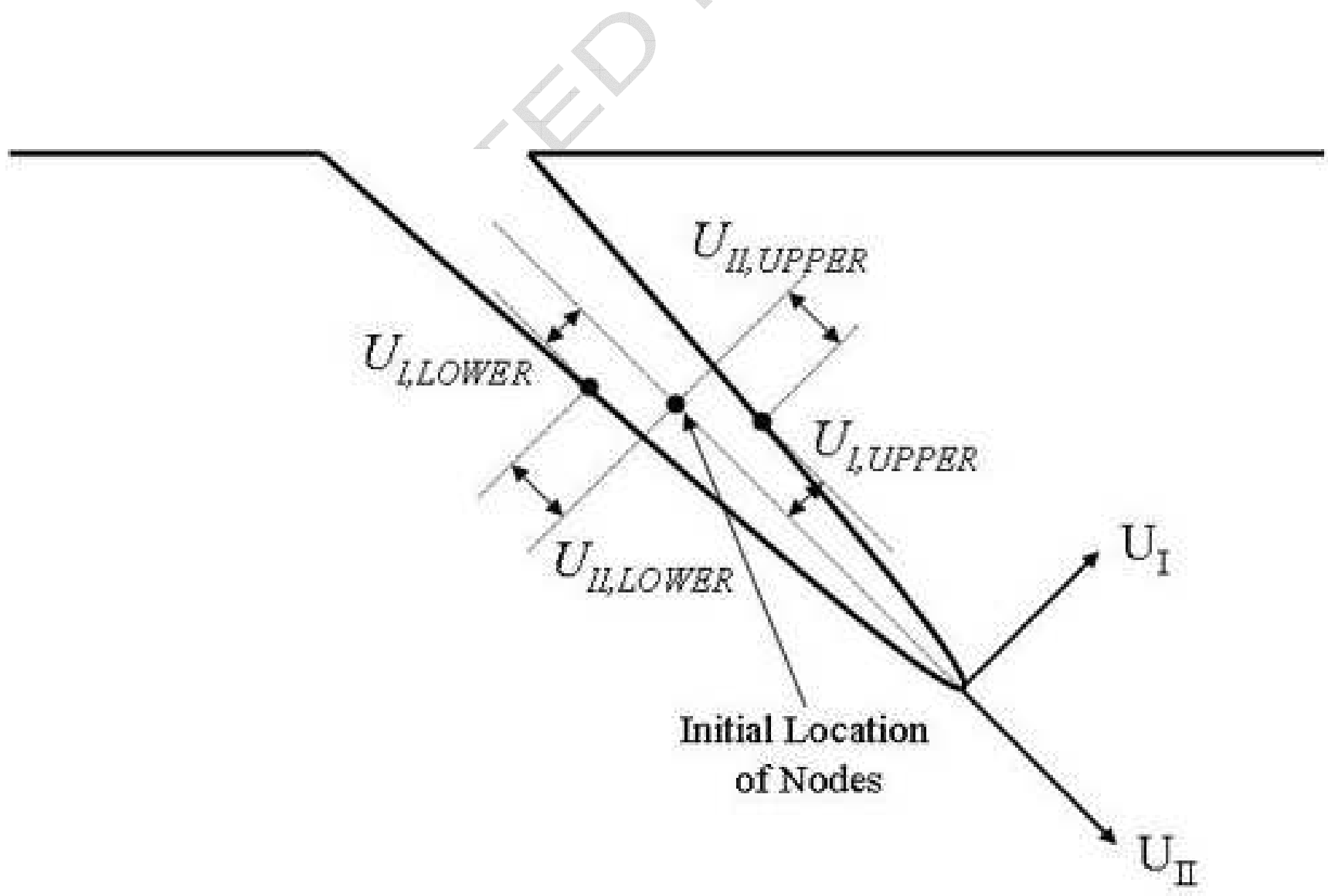


Figure-5

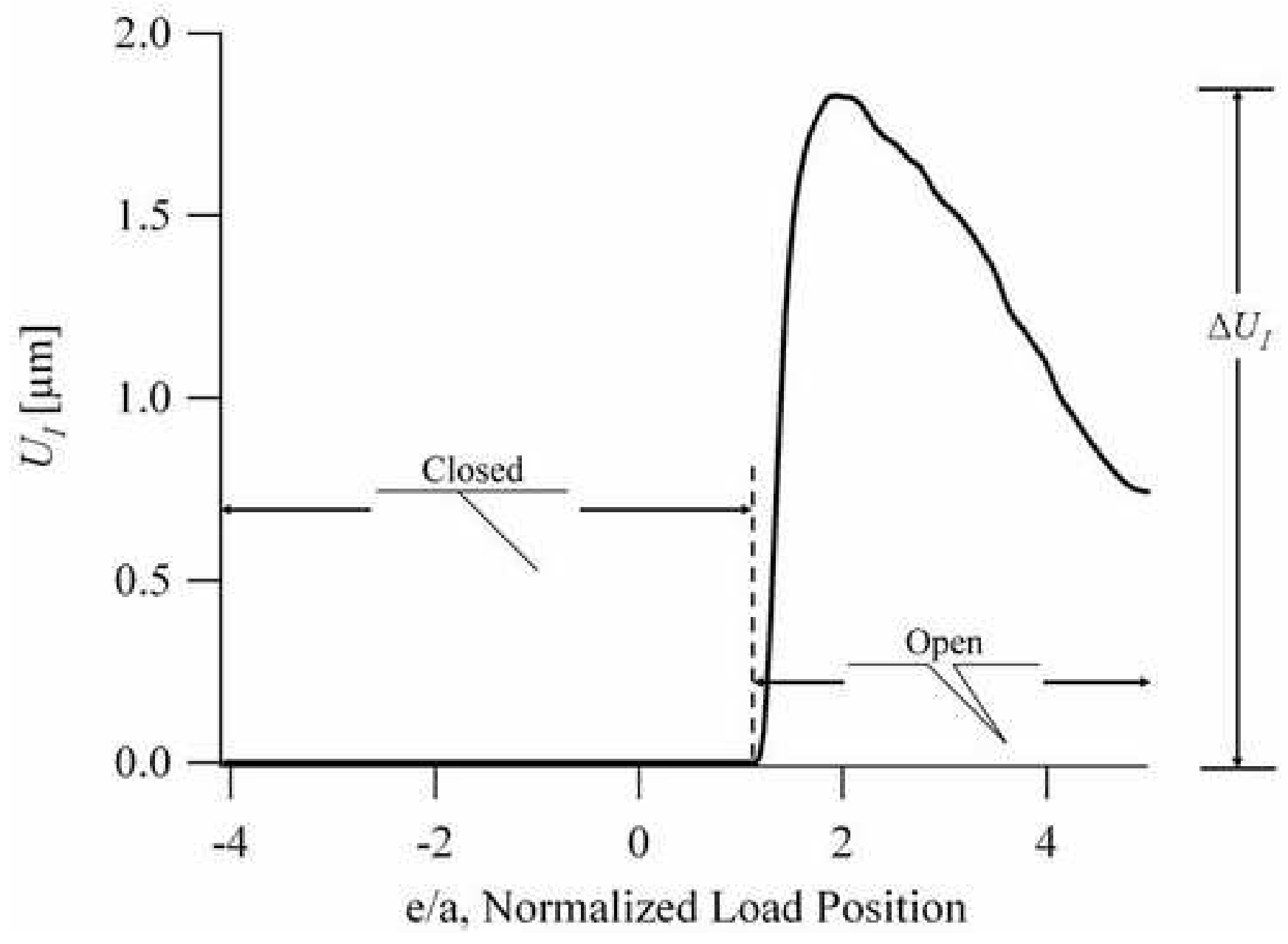


Figure-6

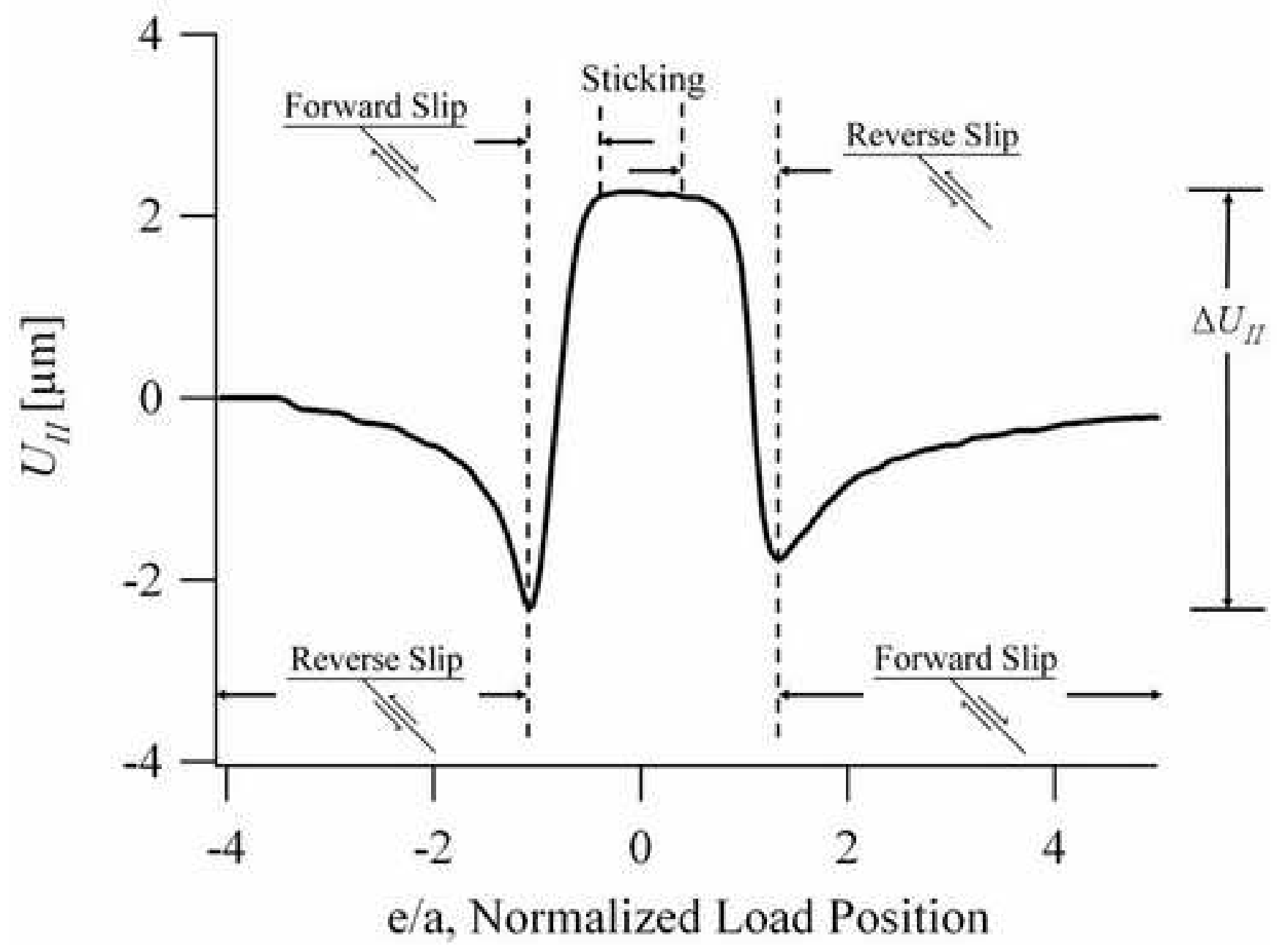


Figure-7

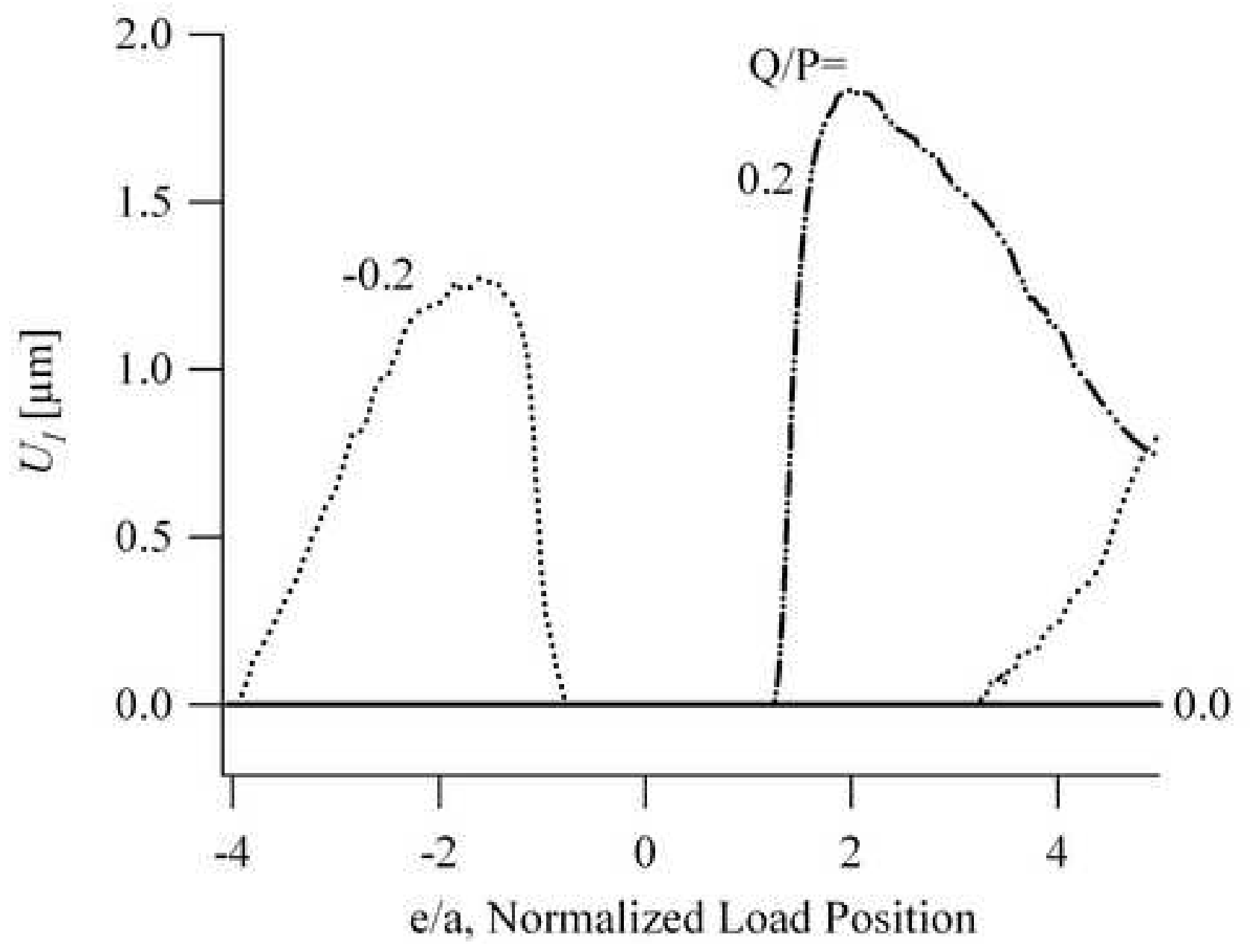


Figure-8

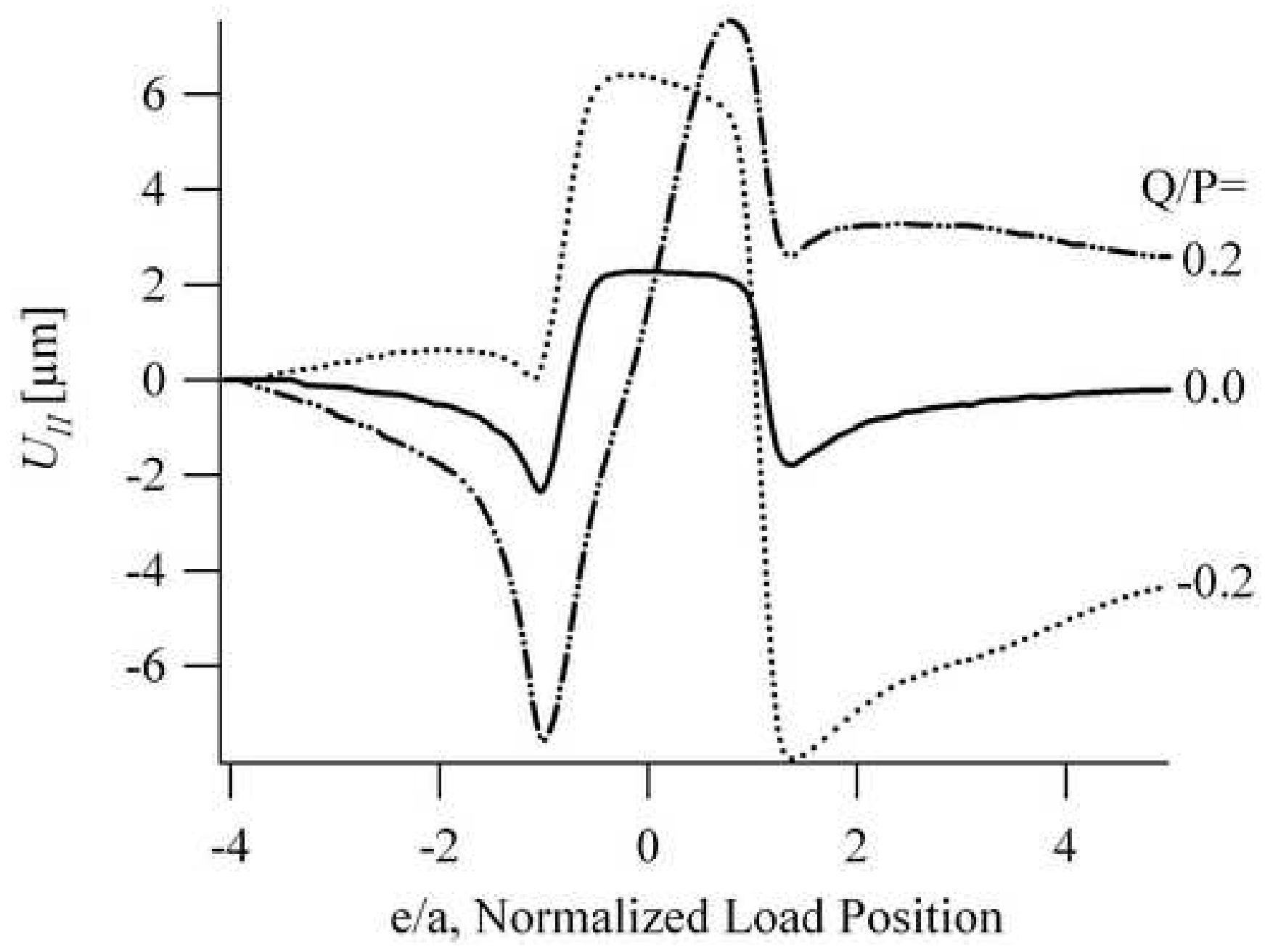


Figure-9

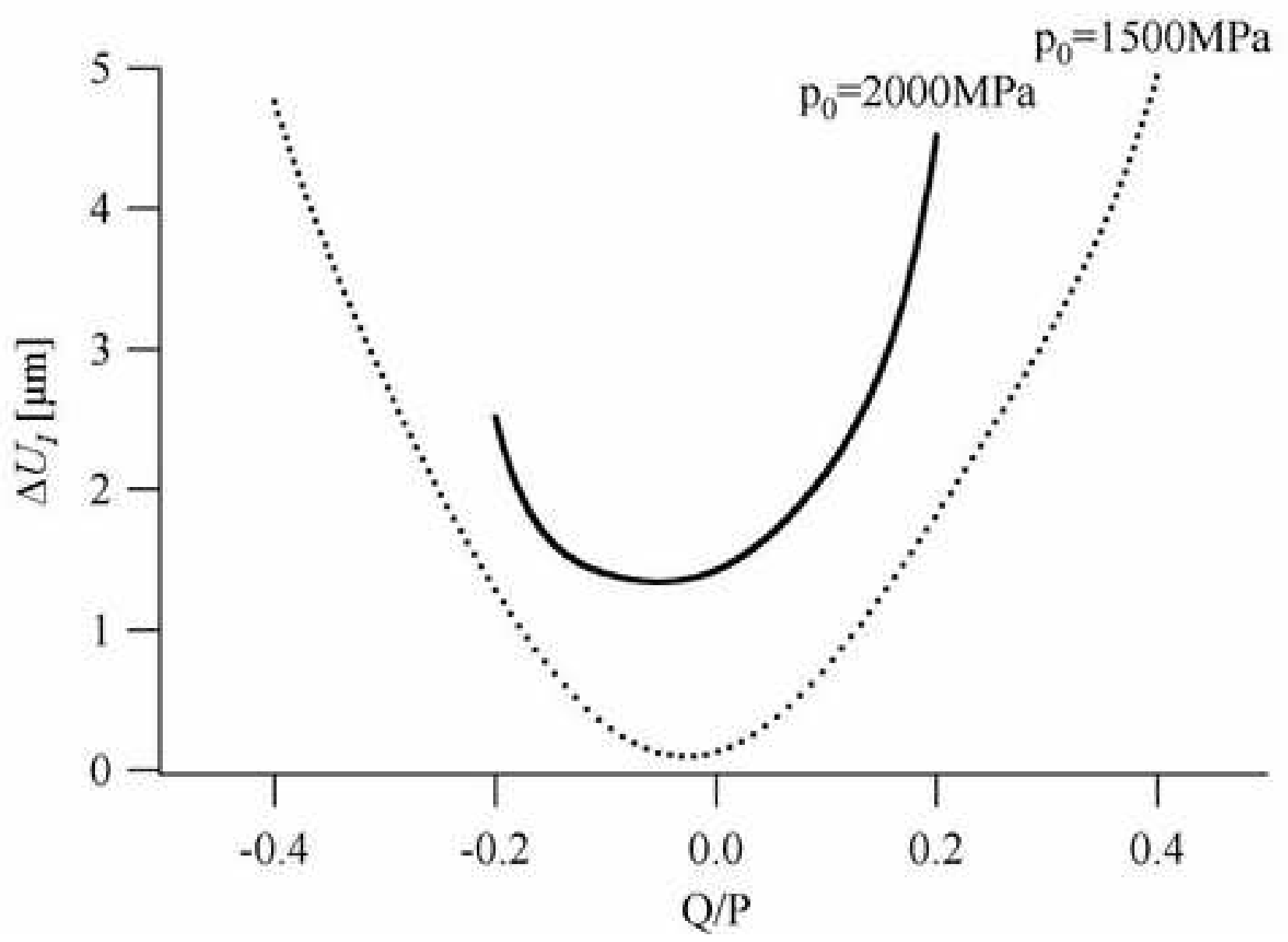


Figure-10

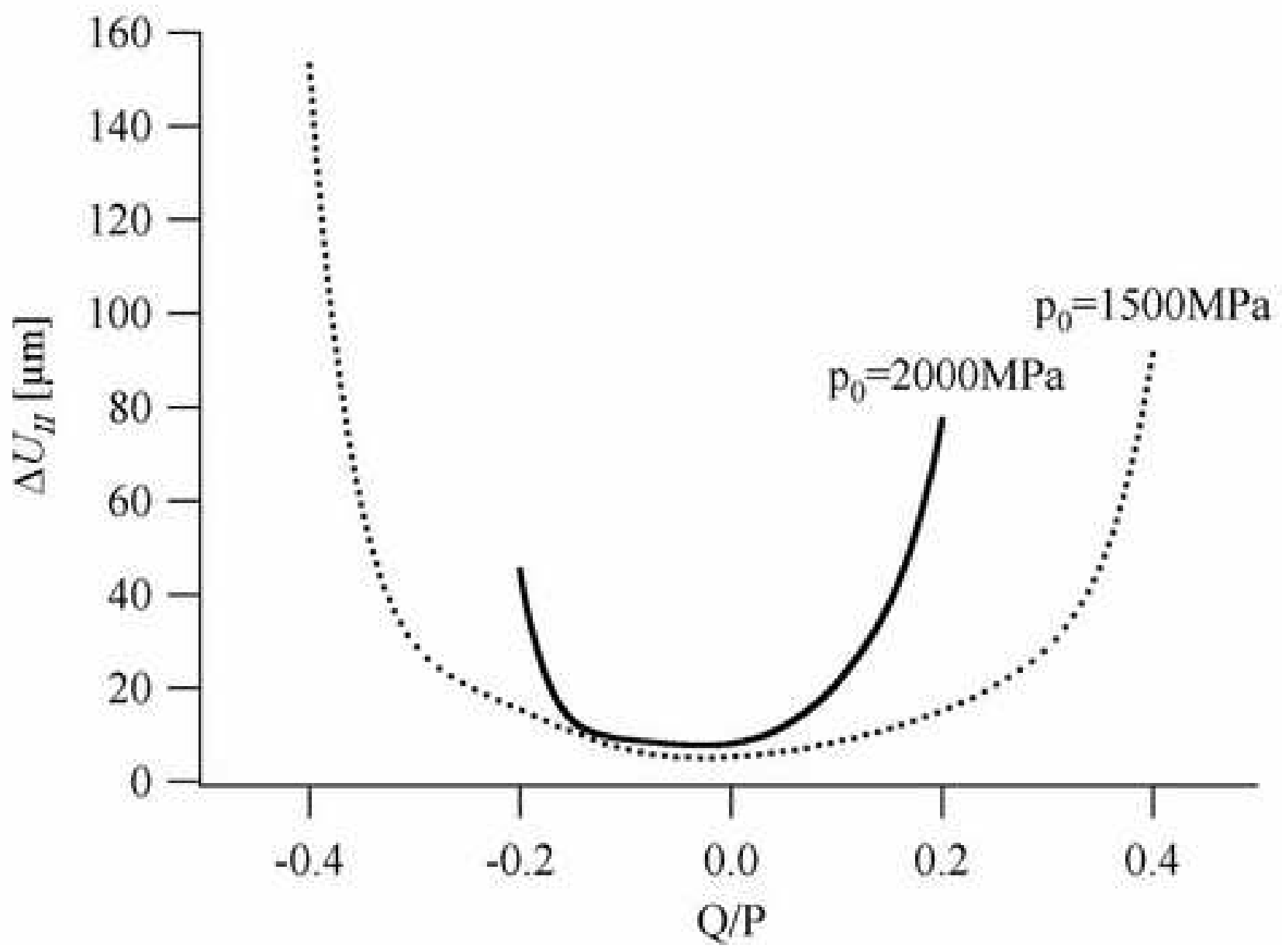


Figure-11

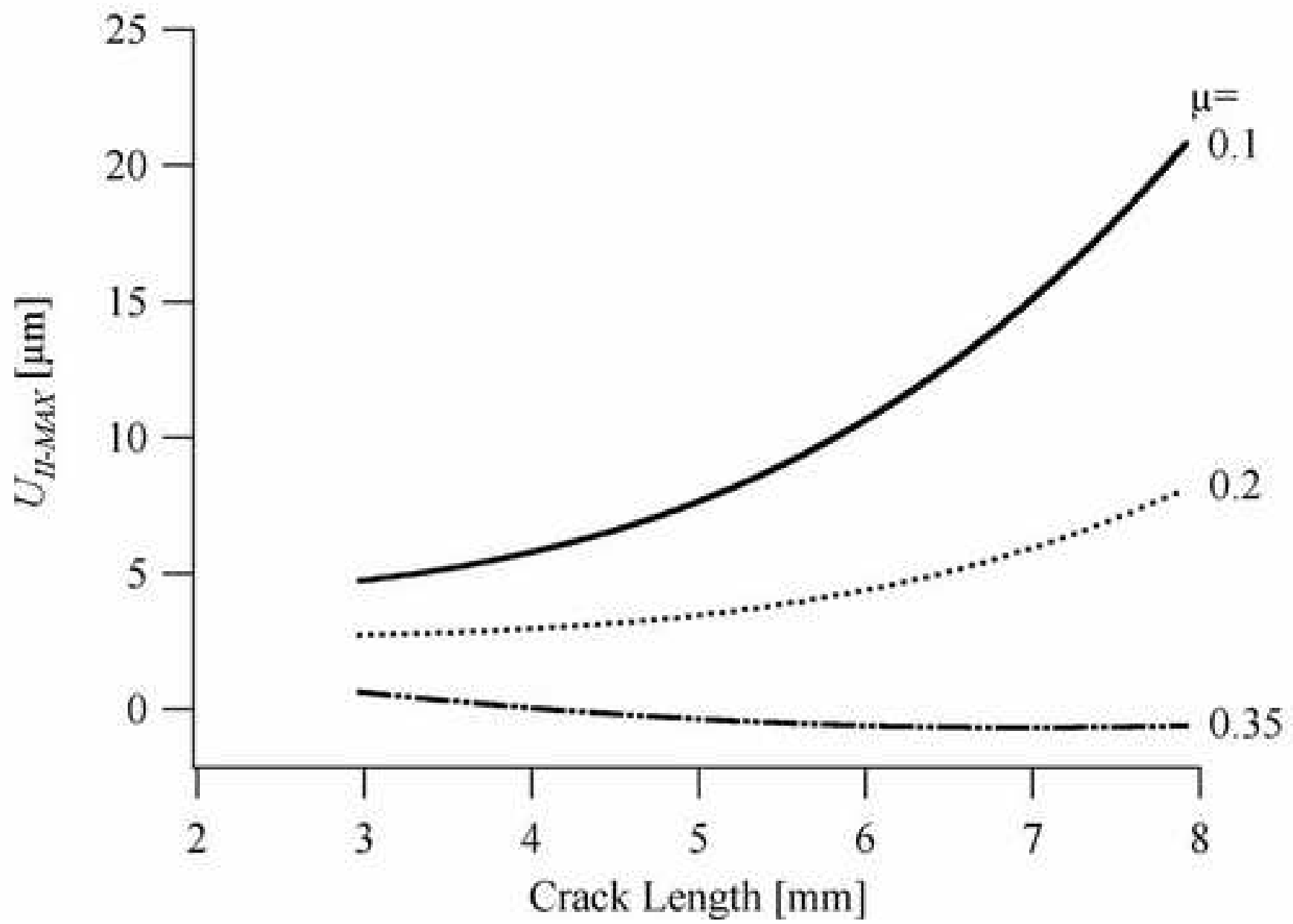


Figure-12

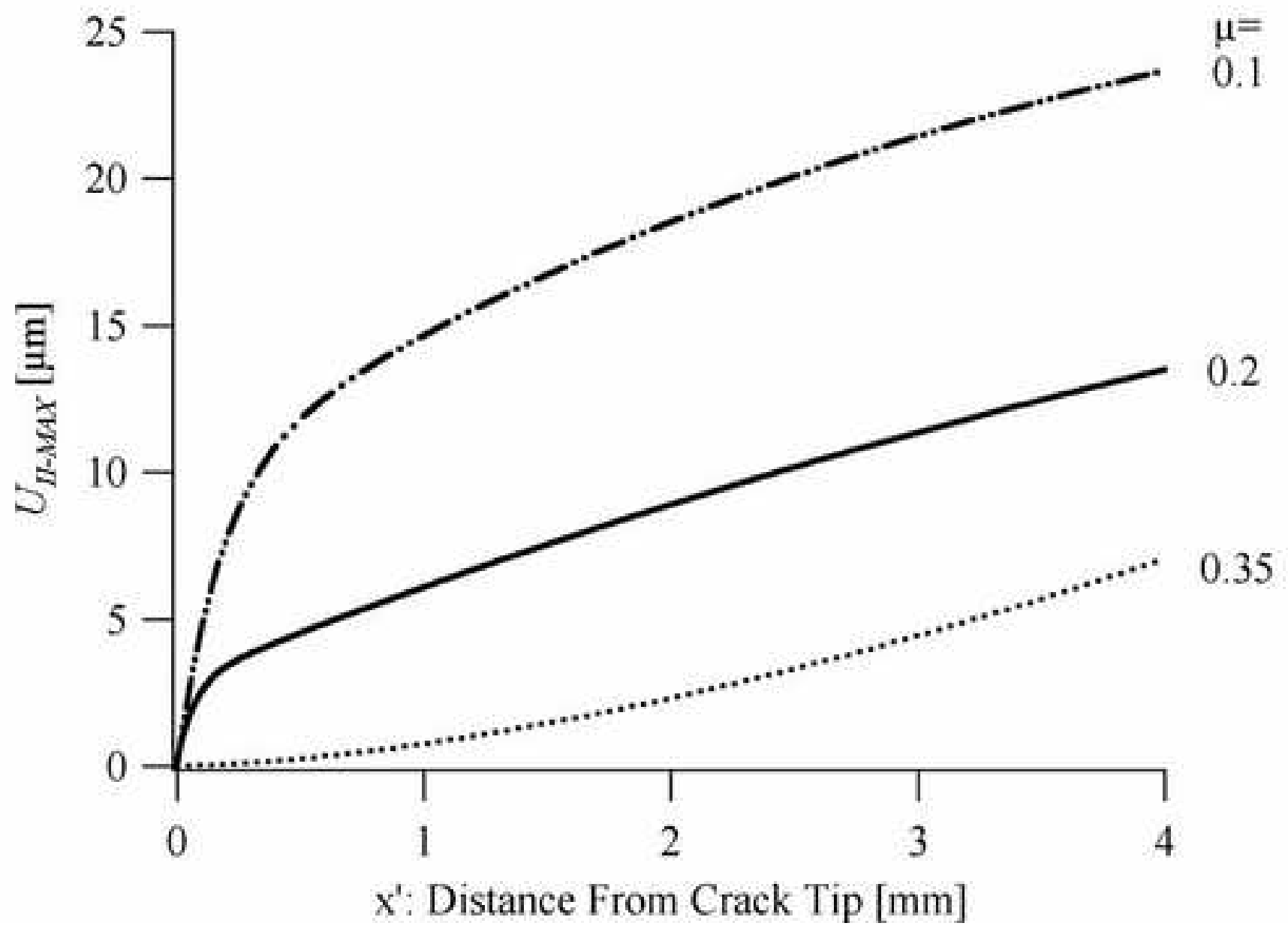


Figure-13

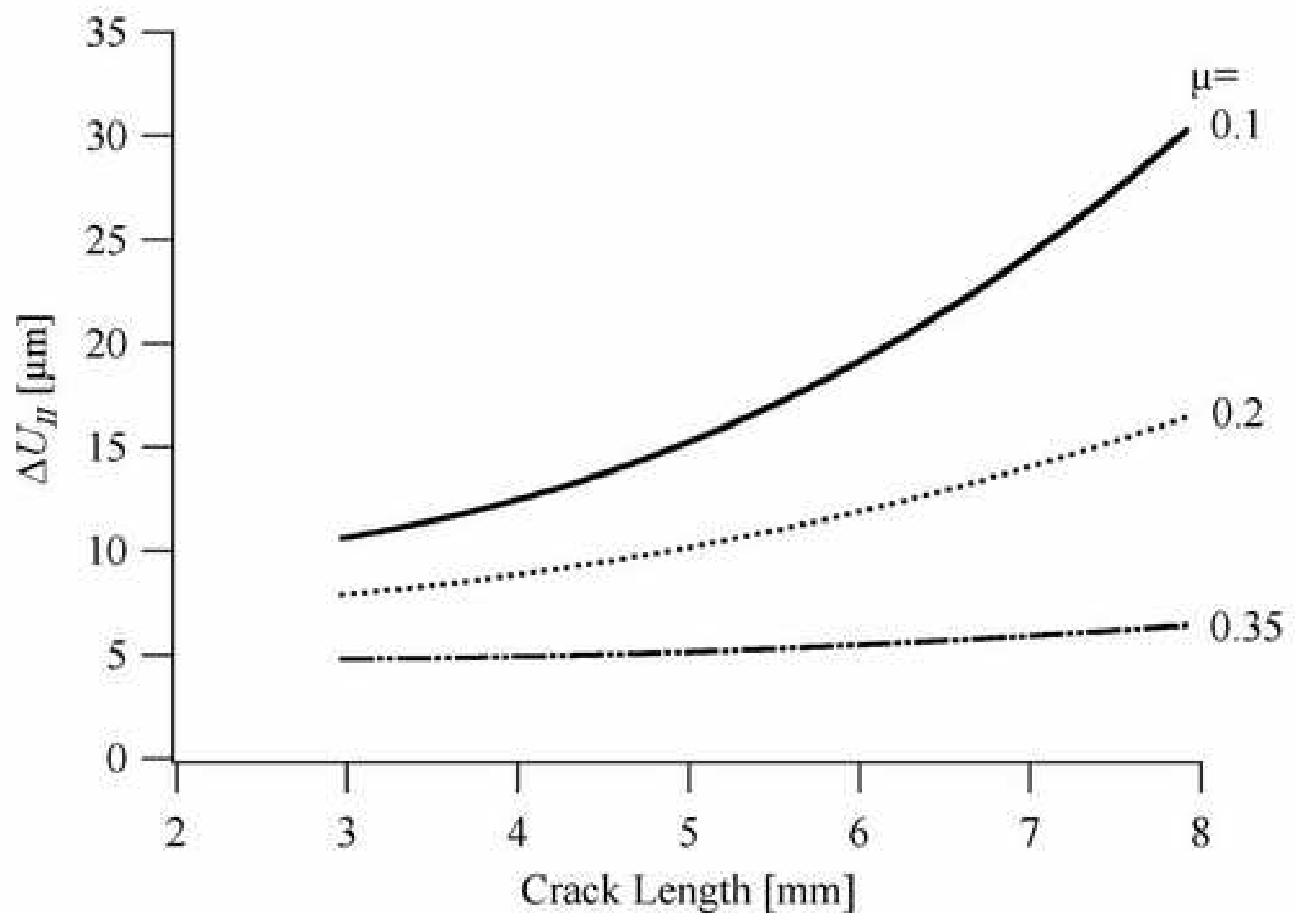


Figure-14

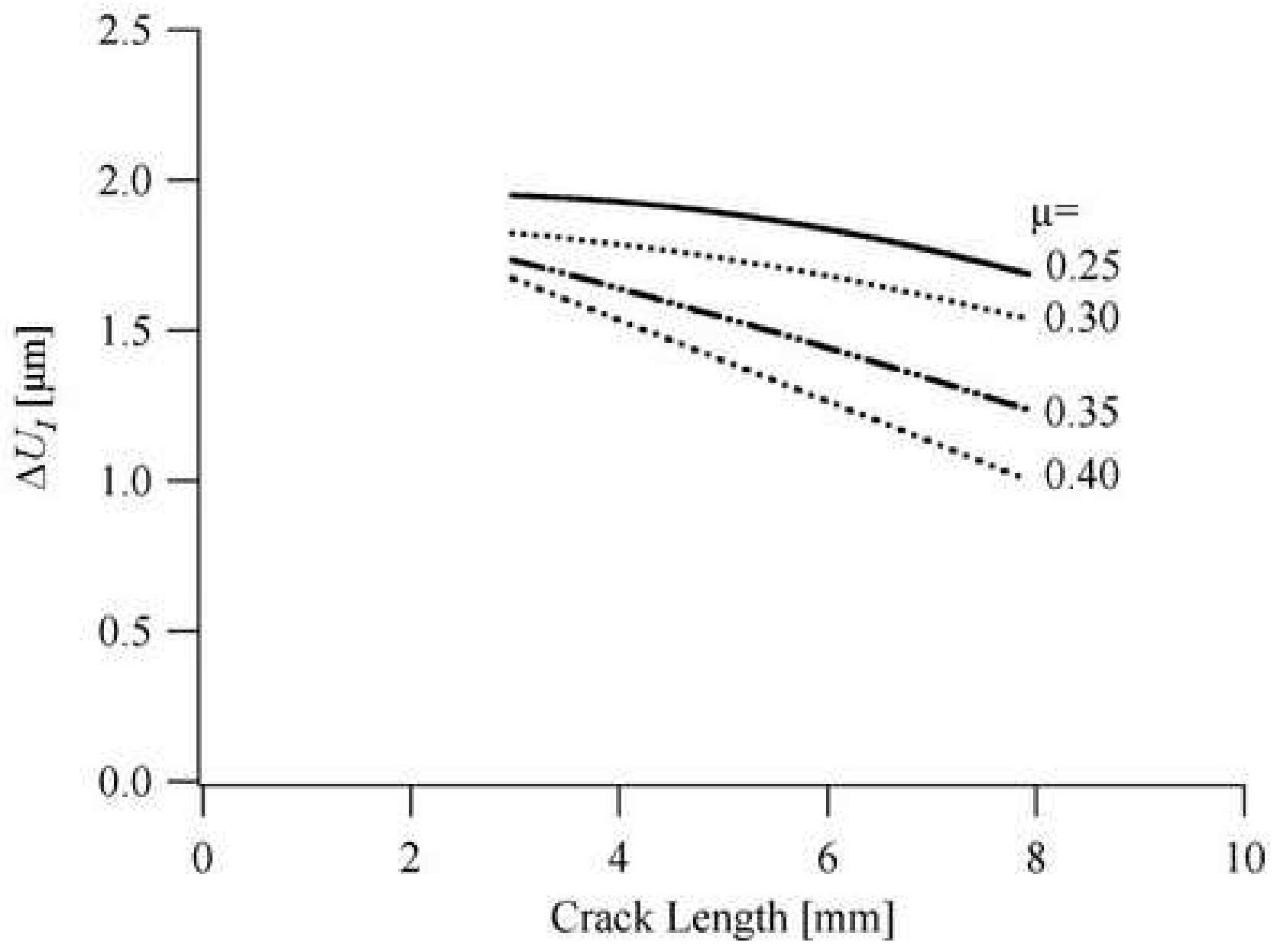


Figure-15

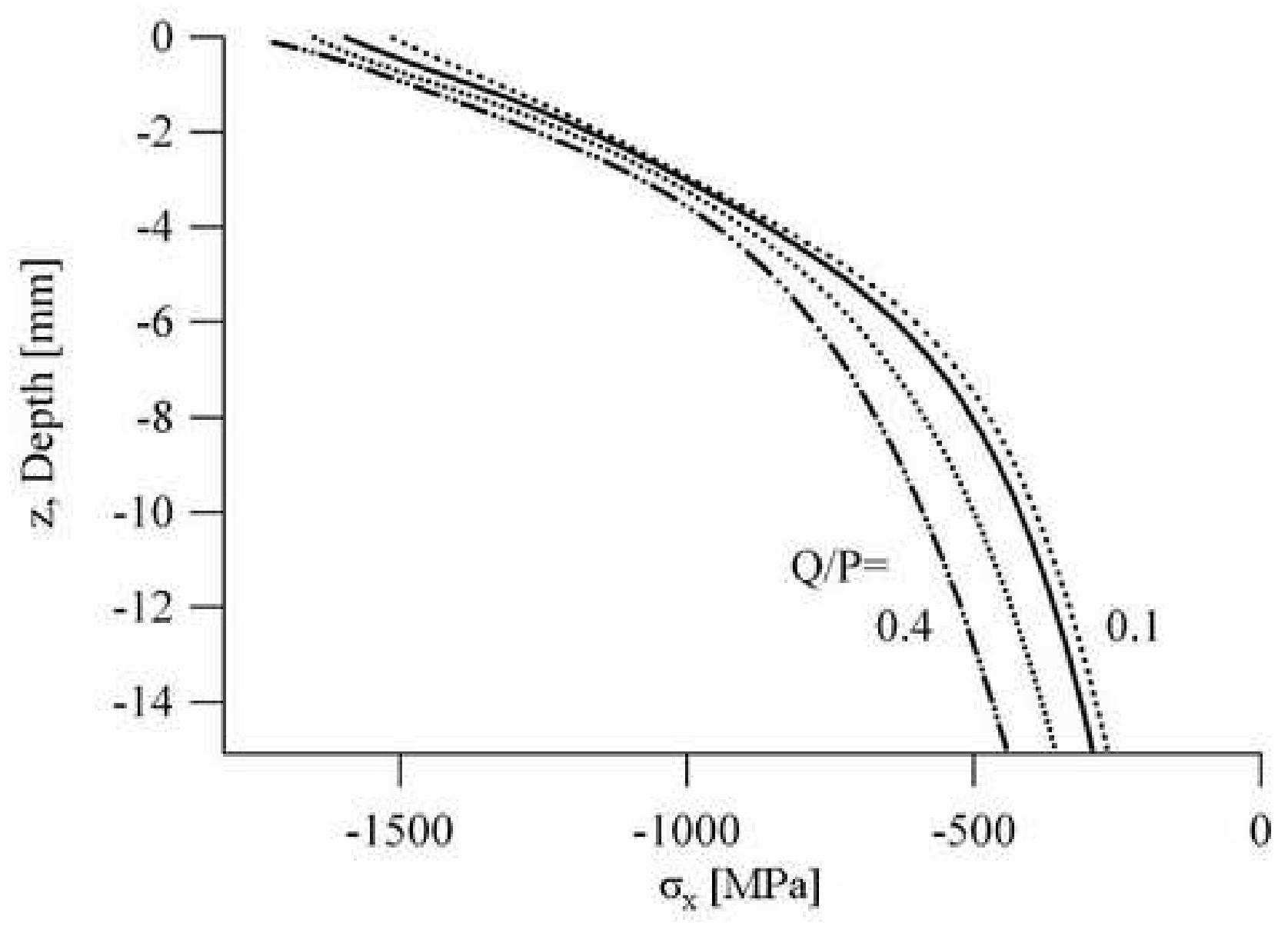


Figure-16

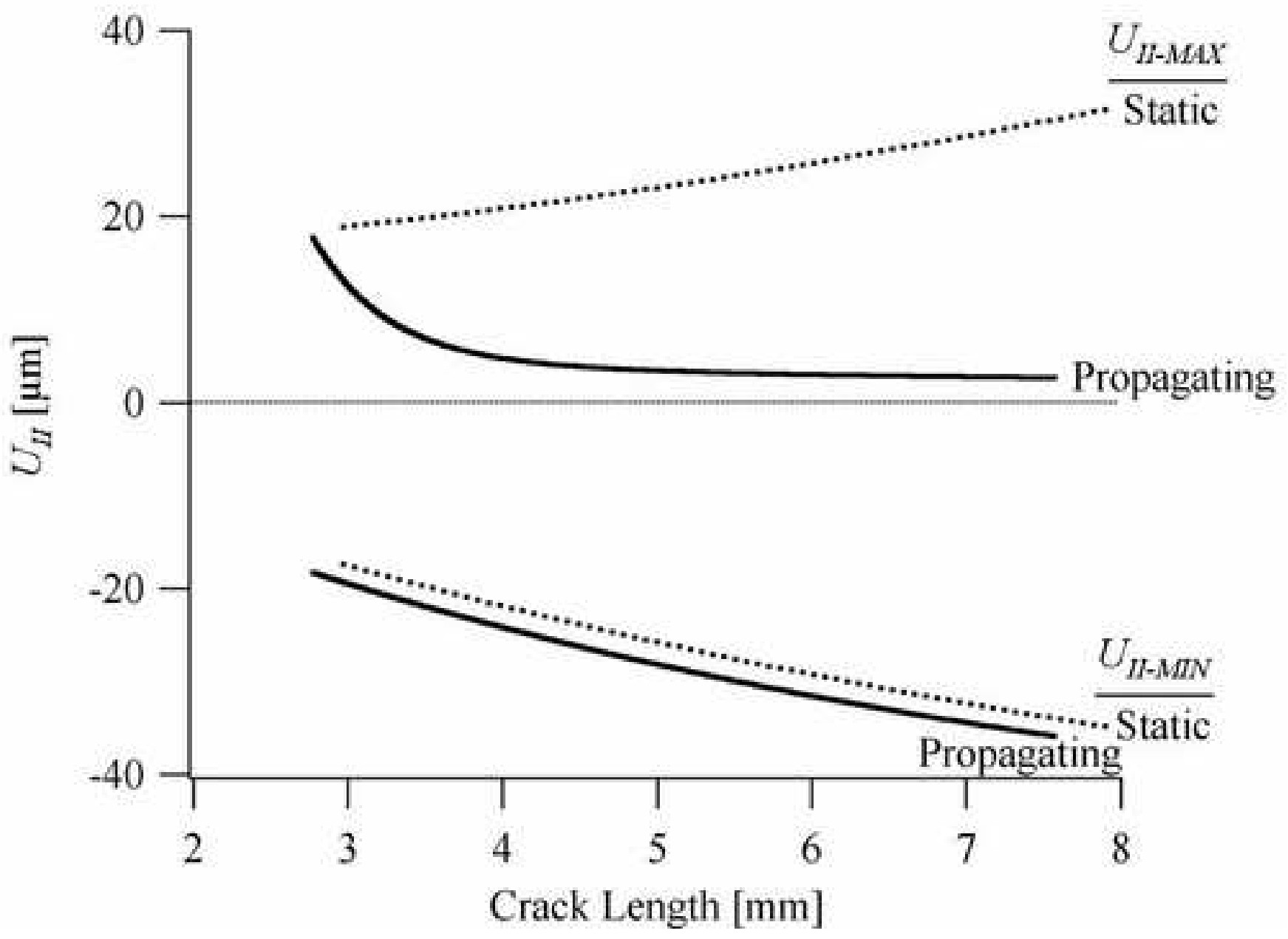


Figure-17

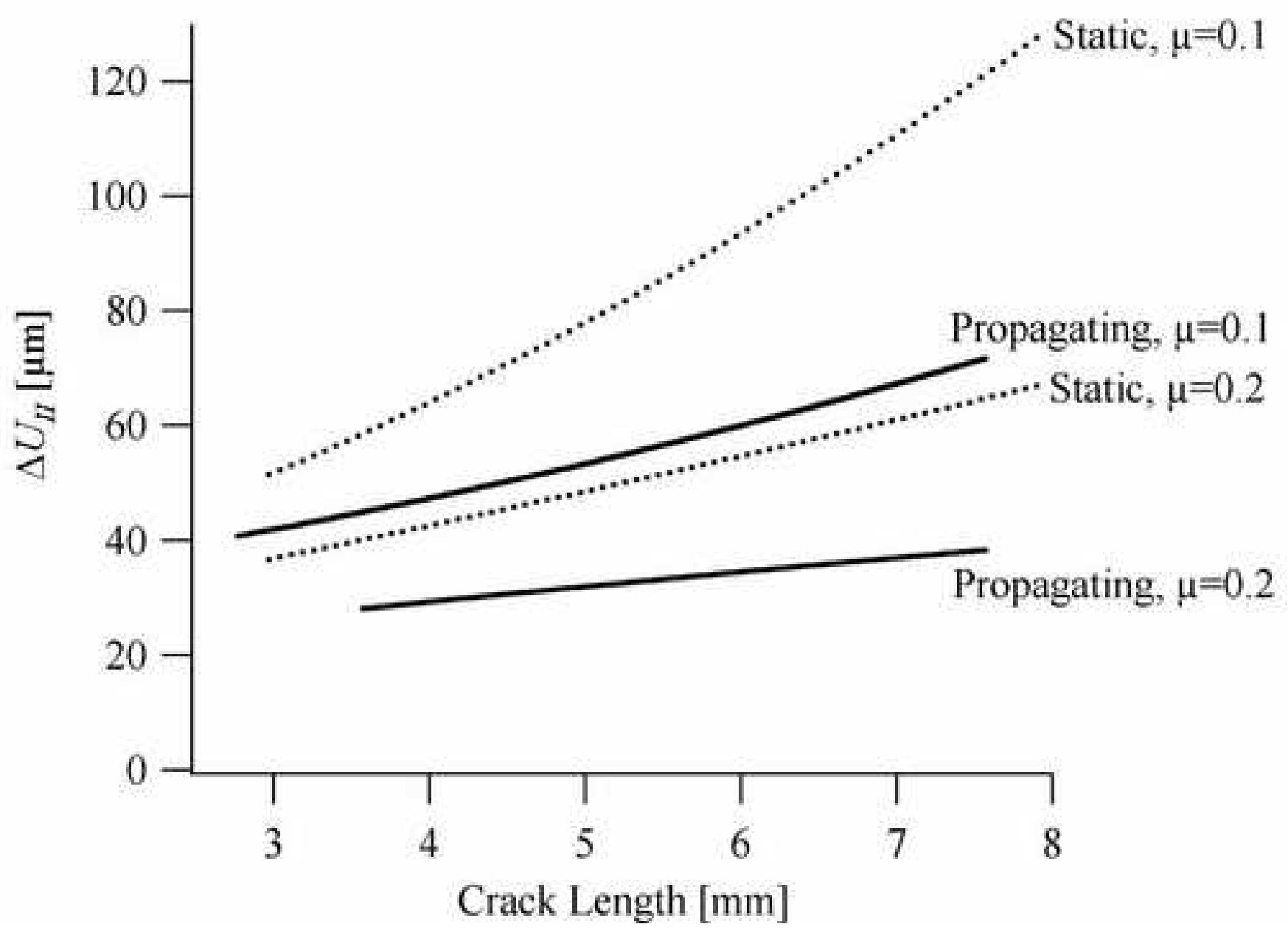


Figure-18

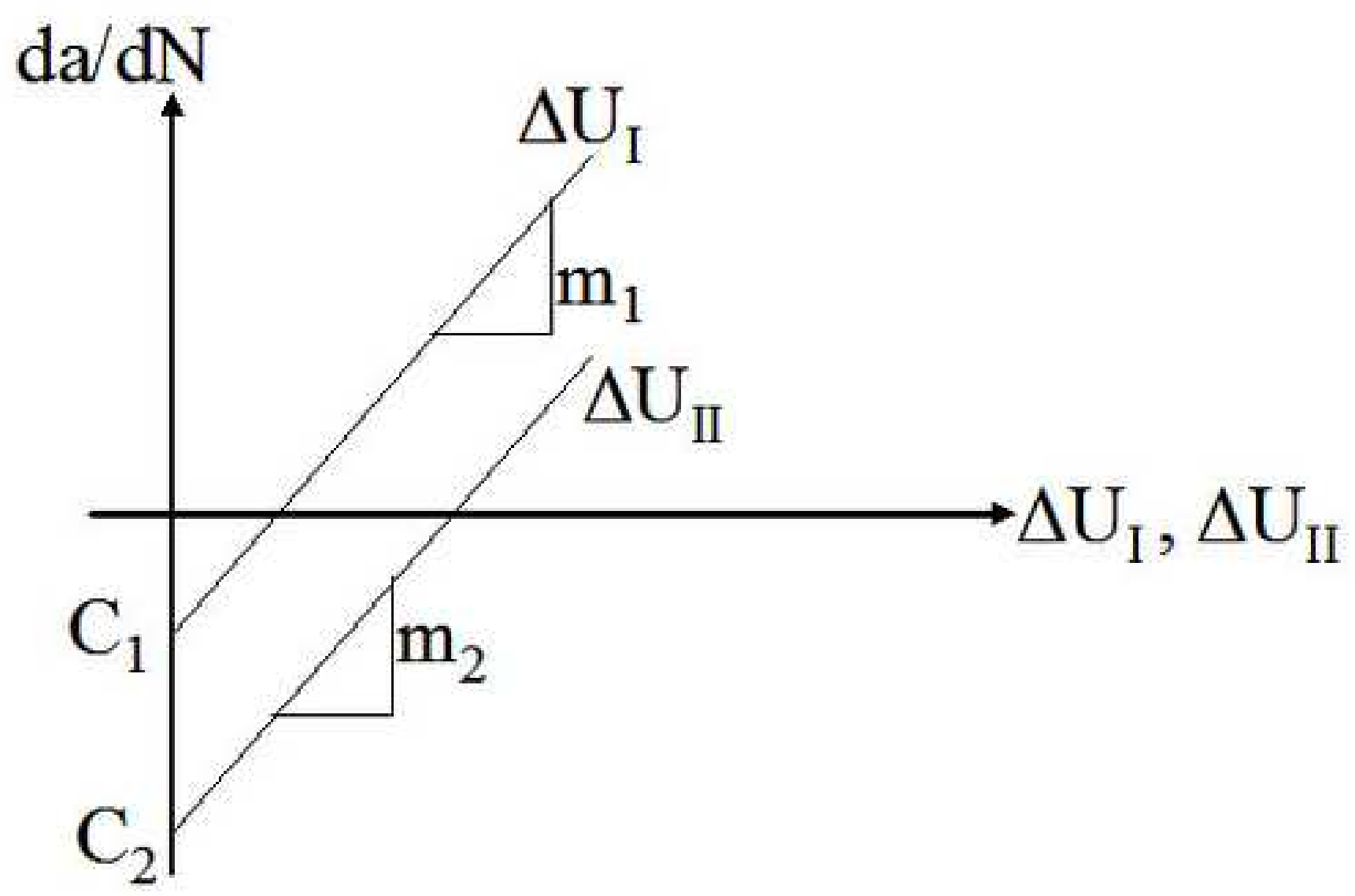


Figure-19

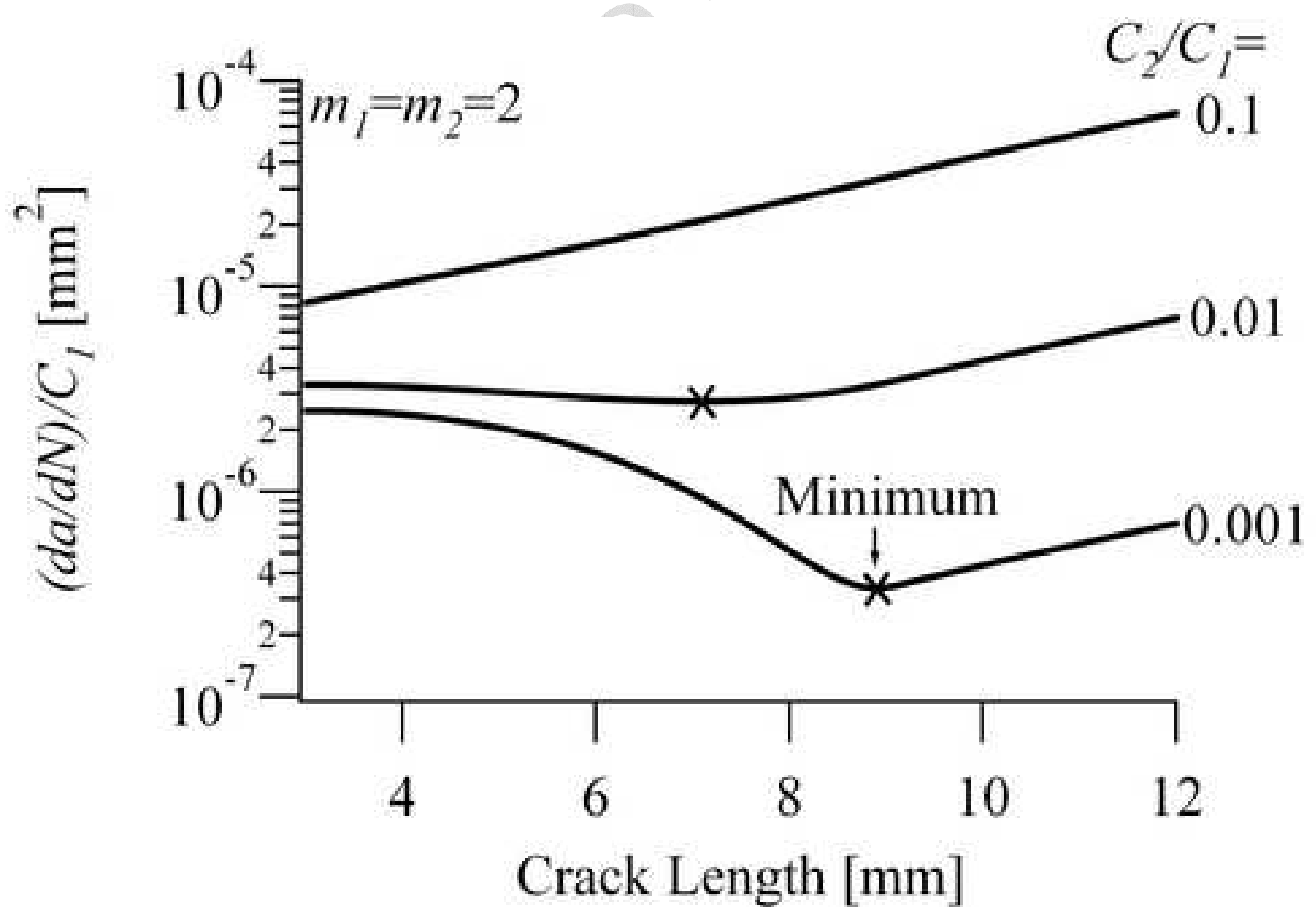


Figure-20

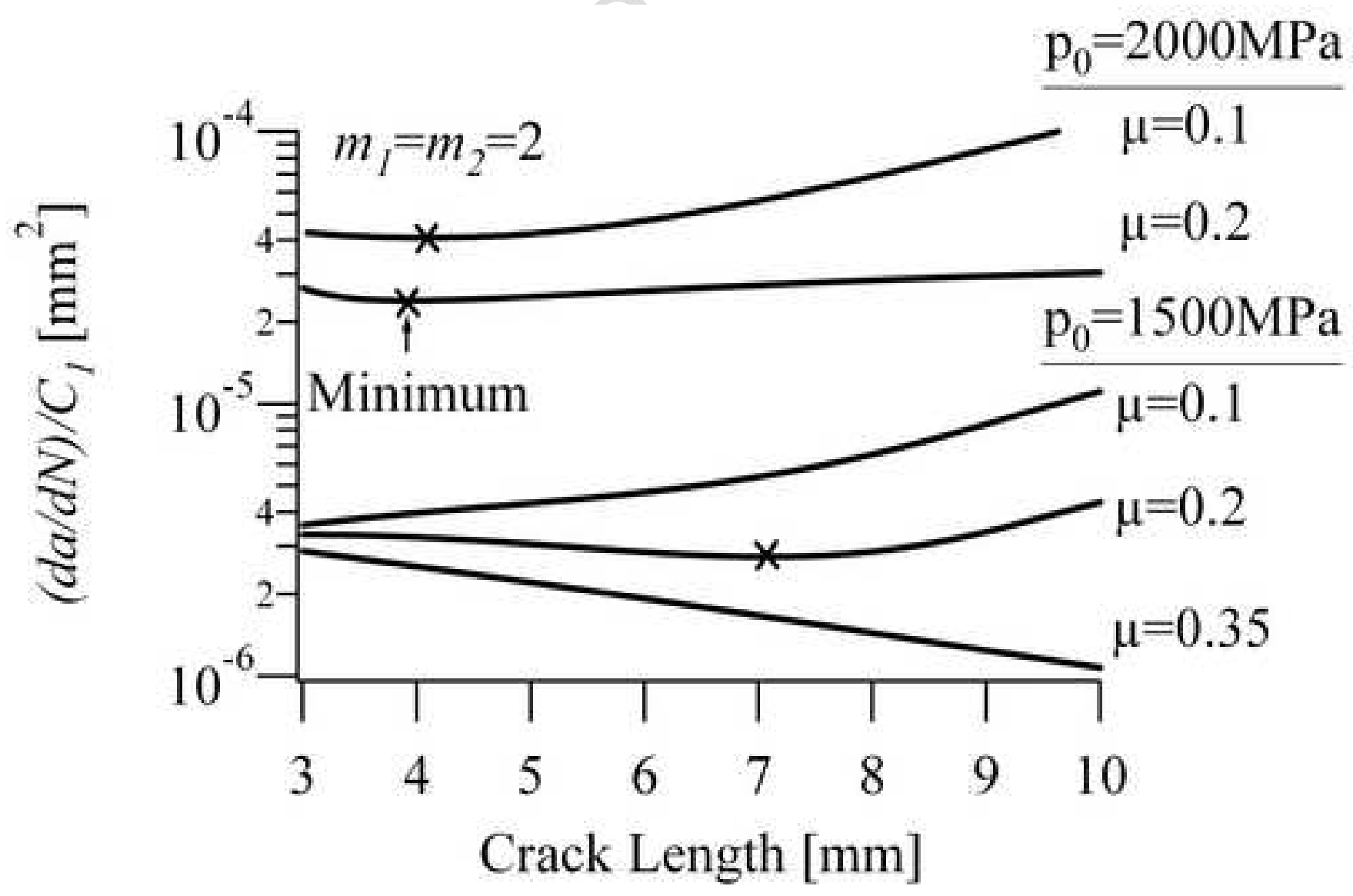


Figure-21

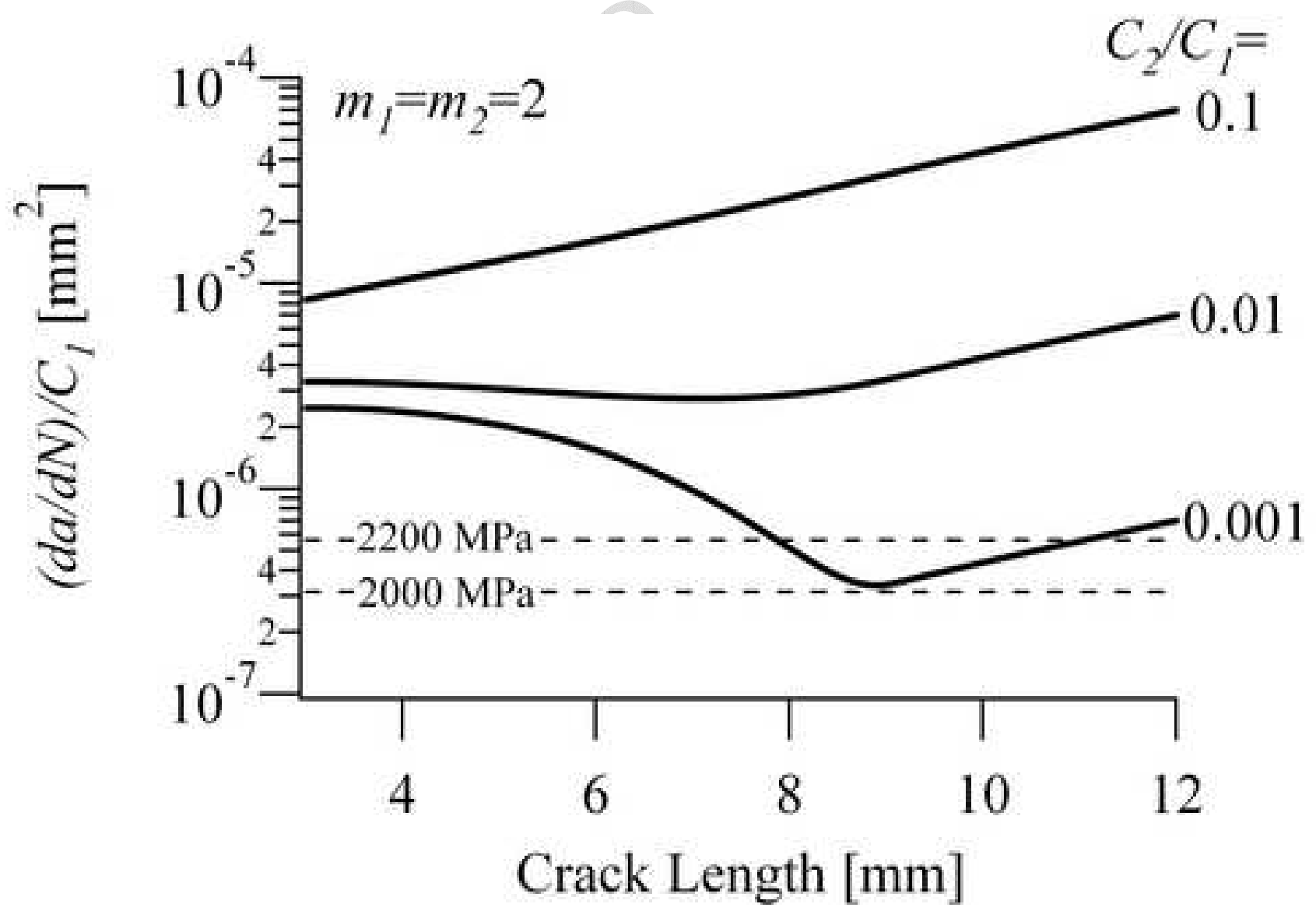


Figure-22

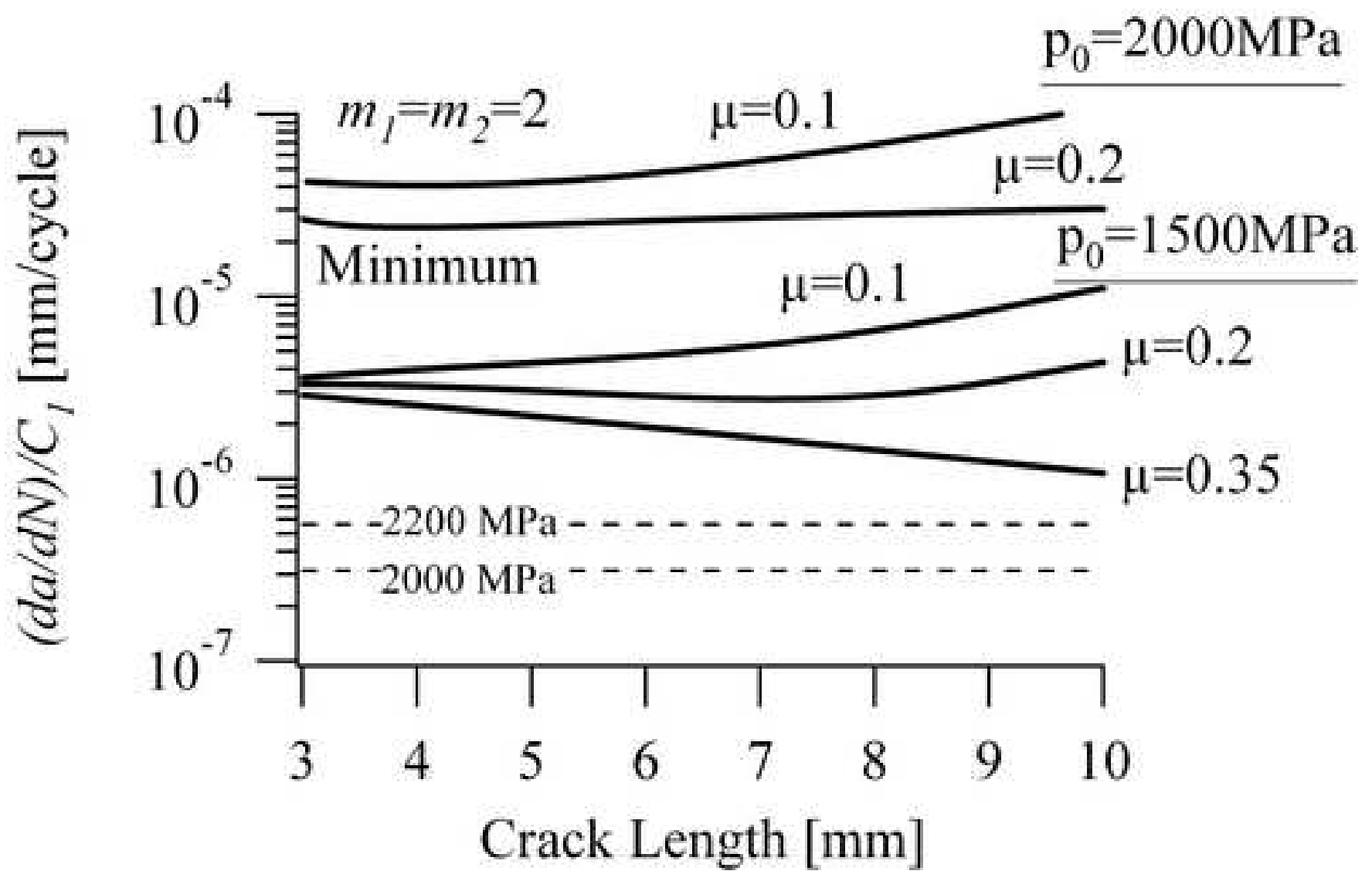

